\title{
Cocaine Drives Aversive Conditioning via Delayed Activation of Dopamine-Responsive Habenular and Midbrain Pathways
}

\author{
Thomas C. Jhou, ${ }^{1,3 \star}$ Cameron H. Good, ${ }^{2 \star}$ Courtney S. Rowley, ${ }^{3}$ Sheng-ping Xu, ${ }^{1}$ Huikun Wang, ${ }^{2}$ Nathan W. Burnham, ${ }^{3}$ \\ Alexander F. Hoffman, ${ }^{2}$ Carl R. Lupica, ${ }^{2 \star}$ and Satoshi Ikemoto ${ }^{1 \star}$ \\ ${ }^{1}$ Behavioral Neuroscience Research Branch and ${ }^{2}$ Electrophysiology Research Section, National Institute on Drug Abuse, National Institutes of Health, US \\ Department of Health and Human Services, Baltimore, Maryland 21224, and ${ }^{3}$ Department of Neurosciences, Medical University of South Carolina, \\ Charleston, South Carolina 29425
}

\begin{abstract}
Many strong rewards, including abused drugs, also produce aversive effects that are poorly understood. For example, cocaine can produce aversive conditioning after its rewarding effects have dissipated, consistent with opponent process theory, but the neural mechanisms involved are not well known. Using electrophysiological recordings in awake rats, we found that some neurons in the lateral habenula (LHb), where activation produces aversive conditioning, exhibited biphasic responses to single doses of intravenous cocaine, with an initial inhibition followed by delayed excitation paralleling cocaine's shift from rewarding to aversive. Recordings in LHb slice preparations revealed similar cocaine-induced biphasic responses and further demonstrated that biphasic responses were mimicked by dopamine, that the inhibitory phase depended on dopamine D2-like receptors, and that the delayed excitation persisted after drug washout for prolonged durations consistent with findings in vivo. c-Fos experiments further showed that cocaine-activated LHb neurons preferentially projected to and activated neurons in the rostromedial tegmental nucleus (RMTg), a recently identified target of LHb axons that is activated by negative motivational stimuli and inhibits dopamine neurons. Finally, pharmacological excitation of the RMTg produced conditioned place aversion, whereas cocaine-induced avoidance behaviors in a runway operant paradigm were abolished by lesions of LHb efferents, lesions of the RMTg, or by optogenetic inactivation of the RMTg selectively during the period when LHb neurons are activated by cocaine. Together, these results indicate that LHb/RMTg pathways contribute critically to cocaine-induced avoidance behaviors, while also participating in reciprocally inhibitory interactions with dopamine neurons.
\end{abstract}

\section{Introduction}

Many abused drugs produce rewarding effects mediated by dopamine (DA) (Wise and Bozarth, 1987; Ikemoto, 2007), while also inducing aversive effects that persist after initial rewarding effects dissipate. These aversive effects may strongly modulate drug-seeking, and are seen after a wide variety of drug rewards, including psychostimulants, opioids, nicotine, and alcohol (Solomon and Corbit, 1973, 1974; Koob et al., 1989; Weiss et al., 1996; Ettenberg et al., 1999; Kenny and Markou, 2001; Rothwell et al., 2009; Riley, 2011). The mechanisms of the aversive effects are not well understood, but have been posited to result from "opponent" processes that work against, and outlast, the initial

Received July 30, 2012; revised Feb. 22, 2013; accepted March 4, 2013.

Author contributions: T.C.J., C.H.G., C.S.R., A.F.H., C.R.L., and S.I. designed research; T.C.J., C.H.G., C.S.R., S.-p.X., H.W., N.W.B., and A.F.H. performed research; T.C.J., C.H.G., and C.S.R. analyzed data; T.C.J. and C.H.G. wrote the paper.

This work was funded by NIH Grants DA032898 and MH094489 (to T.C.J.) and by the National Institute on Drug Abuse Intramural Research Program. We thank Dr. P.J. Vento for helpful comments on the manuscript and Dr. A. Ettenberg for advice establishing the runway technique.

*T.C.J., C.H.G., C.R.L., and S.I. contributed equally to this work.

The authors declare no competing financial interests.

Correspondence should be addressed to Dr. Thomas Jhou, at his present address: Department of Neurosciences, Medical University of South Carolina, 173 Ashley Avenue, Charleston, SC 29425. E-mail: jhou@musc.edu.

C. Good's present address: Translational Neuroscience Branch, Army Research Laboratory, Aberdeen Proving Ground, MD 21005.

DOI:10.1523/JNEUROSCI.3634-12.2013

Copyright $\odot 2013$ the authors $\quad 0270-6474 / 13 / 337501-12 \$ 15.00 / 0$ rewarding effects (Solomon and Corbit, 1974). With prolonged and repeated exposure, these opponent responses are thought to contribute to eventual tolerance and addiction (Koob and Le Moal, 2008b).

Aversive effects of cocaine may be particularly amenable to study as they occur relatively quickly, $\sim 15 \mathrm{~min}$ after individual drug doses (Ettenberg et al., 1999), and are readily revealed using tasks with low reinforcement rates, such as the runway operant model of cocaine-seeking (Ettenberg, 2004). Notably, acute cessation of cocaine intake causes accumbens DA levels to fall below baseline (Weiss et al., 1992), whereas reduced accumbens DA signaling in turn produces conditioned place aversion (Shippenberg et al., 1991; Liu et al., 2008). Mechanisms underlying this post-cocaine DA reduction are unknown, but recent studies have identified cocaine-induced activation of a dense, previously overlooked GABAergic input to midbrain dopamine neurons arising from the rostromedial tegmental nucleus (RMTg), located caudal to the ventral tegmental area (VTA) (Jhou, 2005; Perrotti et al., 2005; Jhou et al., 2009a,b; Kaufling et al., 2009; Balcita-Pedicino et al., 2011). The RMTg, in turn, receives dense glutamatergic afferents from the lateral habenula (LHb) (Herkenham and Nauta, 1979; Jhou et al., 2009b; Kim, 2009), and stimulation of either the LHb or RMTg inhibits $82-97 \%$ of DA neurons (Christoph et al., 1986; Ji and Shepard, 2007; Matsumoto and Hikosaka, 2007; Hong et al., 2011) and contributes to aversive conditioning (Lammel et al., 2012; Stamatakis and Stuber, 2012). We hypoth- 
esized that this circuit contributes to cocaine's aversive properties, but prior reports on RMTg and $\mathrm{LHb}$ responses to cocaine have yielded seemingly paradoxical results. RMTg and LHb neurons exhibit pronounced c-Fos expression after cocaine exposure, suggestive of increased activation (Jhou et al., 2009a; Zahm et al., 2010), but acute recording studies instead show rapid inhibition of LHb and RMTg firing by cocaine (Dougherty et al., 1990; Lecca et al., 2010). We hypothesize this apparent conflict could be explained by a biphasic response, but this has not been tested. Furthermore, the RMTg receives relatively little DA innervation (Jhou et al., 2009b), suggesting that its responses to cocaine would be driven by upstream afferents, such as the LHb, which receives significant DA innervation (Gruber et al., 2007); hence, we tested the above hypotheses using a combination of electrophysiological, anatomical, behavioral, and optogenetic methods.

\section{Materials and Methods}

Animals. Male albino Wistar rats were used for in vivo recording and conditioned place preference (CPP) experiments, whereas Sprague Dawley rats were used for runway and c-Fos experiments (275-350 g of for both strains, Charles River Laboratories). We used 35 rats for in vivo LHb recordings, 38 rats for place preference experiments, 43 rats for runway experiments, 41 rats for optogenetic runway experiments, and 20 rats for c-Fos experiments. Male Sprague Dawley rats 14 to $30 \mathrm{~d}$ old (Charles River Laboratories) were used for in vitro electrophysiology experiments. All protocols were conducted under National Institutes of Health guidelines using the NIH handbook Animals in Research and were approved by the Animal Care and Use Committee (National Institute on Drug Abuse, Intramural Research Program, Baltimore, MD) and the Medical University of South Carolina.

Intravenous catheterization and cocaine injections. Rats were implanted with 0.037 in. diameter silicone tubing (Silastic, Dow Corning) into the jugular vein. Intravenous lines were exteriorized at the back of the neck and flushed every $2 \mathrm{~d}$ with sterile heparinized saline to ensure patency. Lines were flushed again before recording sessions or runway behavioral sessions. During sessions, plastic tubing (PE-50, 0.015 in. inner diameter) was attached to the intravenous line before starting recording, and tubing was filled with either cocaine $(0.1 \mathrm{ml} \times 2.25 \mathrm{mg} / \mathrm{ml}=0.225 \mathrm{mg}$ of cocaine, or $0.75 \mathrm{mg} / \mathrm{kg}$ for a $300 \mathrm{~g}$ rat $)$ or saline $(0.1 \mathrm{ml})$, and the end of the tubing blocked with a metal plug (21 gauge stainless steel, Small Parts). The drug either was delivered manually or via syringe pump (Med Associates).

In vivo electrophysiological recordings of $\mathrm{LH} b$ responses to food cues and intravenous cocaine. Rats used for in vivo LHb recordings were first trained to associate distinct auditory cues with either a food pellet or no outcome. These rats were food restricted to $85 \%$ of their initial body weight by first reducing food intake to 1 pellet daily for 3-4 d, until the target weight was reached, after which food was given to maintain this weight for the remainder of the experiment. Food-predictive and unpredictive cues were either a $1.5 \mathrm{kHz}$ tone, $4 \mathrm{kHz}$ tone, or white noise (counterbalanced). Rats were trained for 1-2 sessions per day, with 100 trials per session. In the first two sessions, the food-predictive cue was presented for $1 \mathrm{~s}$, and a food pellet ( $45 \mathrm{mg}$, BioServ) was delivered $1 \mathrm{~s}$ after cue offset. After food consumption, a $7 \mathrm{~s}$ intertrial interval ensued, after which the next cue was presented. Starting with the third training session, nonrewarded cue trials were introduced on a random $50 \%$ of trials, and a "correct" response was scored if the animal either entered the food tray within $2 \mathrm{~s}$ after rewarded cues, or withheld a response for $2 \mathrm{~s}$ after nonrewarded cues. Rats were judged to have reached criterion when they achieved $90 \%$ accuracy in any 20 -trial block, a criterion met (and usually exceeded) by almost all rats in 4-8 sessions, i.e., 400-800 trials.

At least $3 \mathrm{~d}$ after final cue training, drivable electrode arrays aimed at the $\mathrm{LHb}$ were implanted at stereotaxic coordinates AP $-3.4, \mathrm{DV}-5.8$, $\mathrm{RL}-1.5$, with electrodes angled $10^{\circ}$ toward the midline. Electrodes consisted of a bundle of eight $25 \mu \mathrm{m}$ Formvar-insulated nichrome wires attached to a custom-machined microdrive as previously described
(Jhou et al., 2009a). Electrodes were grounded through a 37 gauge wire attached to a gold-plated pin (Newark Electronics), which was implanted into the overlying cortex, after which the entire assembly encased in dental acrylic (Lang Dental). After a week of recovery, rats were again placed on mild food deprivation, and recordings obtained in sessions consisting of 100 trials of the food-cue task described above, followed by a $15 \mathrm{~min}$ baseline recording period, and then injection of cocaine $(0.75$ $\mathrm{mg} / \mathrm{kg}$, delivered intravenously over $10 \mathrm{~s}$ ). Rats were recorded for 1-2 sessions per day, and electrodes advanced $80-160 \mu \mathrm{m}$ at the end of each session, with at least $2 \mathrm{~h}$ between sessions. The recording apparatus consisted of a unity gain headstage (Neuralynx) whose output was fed to preamplifiers with high-pass and low-pass filter cutoffs of 300 and $9 \mathrm{kHz}$, respectively. Analog signals were converted to 16 -bit values at a frequency of $31.25 \mathrm{kHz}$ using a PCI card (National Instruments) controlled by customized acquisition software (Neuro-Sys), which imposed additional high-pass filtering with a cutoff of $300 \mathrm{~Hz}$. Spikes were initially detected via thresholding to remove signals less than twofold above background noise levels, and signals were further processed using principal component analysis performed by Offline Sorter software (Plexon). Spikes were accepted only if they had a refractory period, determined by $<0.2 \%$ of spikes occurring within $1 \mathrm{~ms}$ of a previous spike, as well as by the presence of a large central notch in the auto-correlogram.

At the end of these experiments, marking lesions were made by passing $200 \mu \mathrm{A}$ of current through each recording wire for $5 \mathrm{~s}$, followed by transcardial perfusion. Brains were sectioned at $40 \mu \mathrm{m}$ and tissue stained for Nissl as described previously (Chou et al., 2002).

Place conditioning. Four groups of animals were tested for place conditioning. In three of these groups, we examined conditioning to intravenous cocaine hydrochloride $(0.75 \mathrm{mg} / \mathrm{kg}$, catalog \#C5776, SigmaAldrich) after three different delays ( 0,15 , and $30 \mathrm{~min}, n=6,12$, and 8 ), whereas in a fourth group $(n=4)$ we examined conditioning to intracranial injections of S-AMPA ( $300 \mathrm{nl}$ of $0.3 \mathrm{~mm}$ in saline, catalog \#A0326, Sigma-Aldrich, ) into the RMTg (coordinates AP -6.2 relative to bregma, $\mathrm{DV}-7.5$ relative to the dura, and $\mathrm{RL}+1.8$; note this coordinate is for Wistar rats, and is slightly different from that for Sprague Dawley rats, which are given in the methods for optogenetic studies). The place conditioning apparatus (Med Associates) consisted of two equal-sized chambers $(28 \mathrm{~cm}$ wide $\times 21 \mathrm{~cm}$ deep $\times 21 \mathrm{~cm}$ high $)$ flanking a small central chamber $(12 \mathrm{~cm}$ wide $\times 21 \mathrm{~cm}$ deep $\times 21 \mathrm{~cm}$ high $)$. One chamber had white walls, a square grid floor, and low overhead light intensity, whereas the other had black walls, parallel bar floors, and a higher overhead light intensity. Each animal was always given drug in one chamber and vehicle in the other, with chambers randomly assigned and counterbalanced across rats. On the first day of each experiment, animals explored all three chambers freely for $15 \mathrm{~min}$, constituting a baseline preference score. Across all animals, there was no overall baseline preference for either chamber. Over the next $4 \mathrm{~d}$, animals were placed into conditioning chambers for $15 \mathrm{~min}$ after receiving vehicle injections during morning sessions (commencing between 9:00 A.M. and 10:00 A.M.) and again after receiving drug injections during afternoon sessions (commencing between 2:00 P.M. and 3:00 P.M.). Animals were placed into chambers immediately after drug infusions for the AMPA experiment, and after a delay of 0,15 , or $30 \mathrm{~min}$ for the intravenous cocaine test. On the sixth day, animals again explored all chambers freely without drug exposure. The posttraining preference score was defined as the number of seconds spent in the drug-paired chamber minus the number of seconds spent in the unpaired chamber. We also calculated each animal's preference shift, defined as the posttraining preference minus the pretraining preference score.

Surgeries and immunohistochemistry for c-Fos experiments. Seven Sprague Dawley rats were used to examine c-Fos after unilateral fasciculus retroflexus (FR) lesion experiments, of which two were excluded due to incomplete lesions. Eleven rats were used to examine LHb c-Fos in conjunction with retrograde tracing, of which three were excluded due to missed tracer injections. Rats in the first experiment received electrolytic lesions of the FR, made by delivering $2 \mathrm{~mA}$ of direct current (positive polarity) for $30 \mathrm{~s}$ into the FR at coordinates AP - 3.9-4.0, DV - 5.8-6.1, RL 1.5-1.9, with the electrode angled 10 degrees toward the midline. Rats in the second experiment received injections of the retrograde tracer 
cholera-toxin B (CTB; $1 \%$ in saline, List Biological) into the following stereotaxic coordinates relative to bregma: VTA AP -6.0 , DV -8.5 , $\mathrm{RL}+2.1$, or RMTg AP -7.1, DV -8.4, RL + 1.9. These stereotaxic coordinates are for Sprague Dawley rats, whereas RMTg coordinates for Wistar rats are given in the methods for $\mathrm{CPP}$ experiments.

Three to $4 \mathrm{~d}$ after lesions, or 6-12 d after tracer injections, rats were injected intraperitoneally with $10 \mathrm{mg} / \mathrm{kg}$ cocaine, then perfused $1 \mathrm{~h}$ later with $10 \%$ formalin ( $100 \mathrm{ml}$ over $5 \mathrm{~min}$ ), followed by $10 \%$ formalin with $15 \%$ sucrose, for cryoprotection. Brains were cut on a freezing microtome 90 min after start of the perfusion, and sections were immunostained for c-Fos as previously described (Jhou et al., 2009b). In brief, tissue was incubated overnight in rabbit anti-c-Fos antibody, 1:50k dilution (EMD Millipore) diluted to 1:100,000 in PBS with $0.25 \%$ Triton-X with $0.01 \%$ sodium azide, followed by incubation $30 \mathrm{~min}$ in biotinylated donkey anti-rabbit secondary antibody (Jackson Immunoresearch) diluted 1:1000 in PBS, then $1 \mathrm{~h}$ in avidin-biotin complex (Vector Laboratories) and $10-15 \mathrm{~min}$ into $0.05 \%$ diaminobenzidine tetrahydrochloride (catalog \#D5637, Sigma-Aldrich) in PBS with $0.01 \%$ hydrogen peroxide and $0.05 \%$ ammonium nickel (II) sulfate hexahydrate (catalog \#A-1827, Sigma-Aldrich). After the development of c-Fos immunohistochemistry, tissue sections were placed into a $1: 10 \mathrm{k}$ dilution of mouse anti-NeuN antibody (EMD Millipore), or for CTB using 1:50k dilution of goat antiCTB antibody (List Biological), followed by appropriate secondary, ABC, and DAB steps as outlined above.

For each anatomical region in each individual, NeuN, CTB, and c-Fosimmunoreactive neurons were counted in 3-4 $40 \mu \mathrm{m}$ sections, spaced $240 \mu \mathrm{m}$ apart and matched across subjects. NeuN or CTB-labeled neurons were counted only if a prominent nucleus, visible as a central region of reduced immunoreactivity, was apparent. Hence, stereological bias should affect quantitation of neurons to approximately the same degree as c-Fos-labeled nuclei. Because the dependent variable in these experiments is the relative proportion, and not the absolute number, of labeled c-Fos and NeuN/CTB neurons, unbiased stereological methods were not used, and would not be expected to alter the results (Saper, 1996).

Runway experiments in lesioned and unlesioned rats. Excitotoxic lesions of the RMTg were made using $25-50 \mathrm{nmol}$ of quinolinic acid ( $100 \mathrm{~mm}$ in 250-500 nl). Excitotoxin was injected using compressed air delivered into drug-filled glass pipettes pulled to a fine tip (10-20 $\mu \mathrm{m}$ tip diameter). Excitotoxin was injected over the course of 30-60 s, after which 5 min were allowed to elapse before the pipette was withdrawn. Lesion placements were verified by immunostaining for NeuN. Electrolytic lesions of the FR were made by injecting $2 \mathrm{~mA}$ of current for 30 s into the FR using a constant current source.

After 7-10 d of recovery from surgery, rats were trained on a runway apparatus (Med Associates) consisting of an opaque plastic corridor 152 $\mathrm{cm}$ long $\times 10 \mathrm{~cm}$ wide $\times 17 \mathrm{~cm}$ high. Start and goal compartments extended from either end of the runway, and were $25 \mathrm{~cm}$ long $\times 10 \mathrm{~cm}$ wide $\times 17 \mathrm{~cm}$ high. Electronically operated doors separated the start/goal boxes from the intervening runway. Animals were initially food deprived to $85 \%$ of baseline body weight as described above, and then given $2-4$ training/habituation trials in which rats received $180 \mathrm{mg}$ of food pellets on arriving in the goal box. Animals that did not reach the goal box within $60 \mathrm{~s}$ by the fourth training trial were excluded from further study. After food training, animals received seven trials in which only cocaine $(0.75 \mathrm{mg} / \mathrm{kg}$, i.v. $)$ dissolved in $5 \mathrm{mg} / \mathrm{ml} \mathrm{saline}$, and delivered at a rate of 25 $\mu \mathrm{l} / \mathrm{s}$ was delivered upon triggering a photobeam in the goal compartment. In each trial, rats were placed in the start box, and after a $20 \mathrm{~s}$ delay all doors were opened and rats were allowed to move freely until they reached the goal box, or until $10 \mathrm{~min}$ had elapsed. After reaching the goal box, doors were closed, cocaine was delivered, and the rat was left in the goal box for $5 \mathrm{~min}$. If rats did not reach the goal box within $10 \mathrm{~min}$ after first leaving the start box, they were removed from the runway and the trial latency recorded as a "timeout". Run latencies and reversals were determined by a computer monitoring six photoemitter/detector pairs placed at regular intervals along the runway.

Runway experiments using optogenetic inhibition. Twenty-two Sprague Dawley rats received bilateral injections into the RMTg (stereotaxic coordinates AP $-7.1, \mathrm{DV}-8.4$, RL \pm 1.9 ) of $250 \mathrm{nl}$ of adeno-associated virus (AAV) serotype $2 / 2$ containing archaerhodopsin from Halorubrum
TP009 (ArchT) (Chow et al., 2010) under control of the CAG promoter (University of North Carolina, Vector Core). Although the CAG promoter is considered to be ubiquitous, i.e., active in both neurons and glia, AAV serotype $2 / 2$ has been widely reported to selectively infect neurons, with little or no glial expression (Burger et al., 2004). During the same surgery, rats received bilateral implants of optical fibers (200 $\mu \mathrm{m}$ core, numerical aperture 0.37 , Thorlabs), with the fiber tip terminating at one end in the RMTg, and the exposed end of the fiber terminating in a metal 2-mm-diameter ferrule (Precision Fiber Products) which would allow a light source to be attached at the time of experiment. After 2 weeks of recovery, rats were initially screened to assess opsin expression efficiency using a Pavlovian approach task in which a food pellet was dispensed noncontingently into a food tray every $30 \mathrm{~s}$, while laser light $(532 \mathrm{~nm}$ continuous illumination, $7.5 \mathrm{~mW}$ per hemisphere) was switched on and off every $60 \mathrm{~s}$. Locomotor distance traveled during light-on and light-off epochs was measured in arbitrary units using video analysis software (Neuro-Sys), and the ratio of distances traveled during light-on versus light-off epochs was calculated. Rats in which this ratio was $<1.4$, i.e., in which locomotor distance during laser-on periods was not at least $40 \%$ higher than during laser-off periods, were excluded from further study; subsequent histological analysis showed that these animals typically had optical fibers located $>500 \mu \mathrm{m}$ from the RMTg center. Nonexcluded rats were then run on the runway task as described above, i.e., with 2-4 initial training trials using a food reward, followed by seven trials in which entering the goal box caused delivery of $0.75 \mathrm{mg} / \mathrm{kg}$ cocaine. Just before the start of each trial, two fiber optic cables were mated to the two exposed ferrules using zirconia sleeves (Precision Fiber Products). At the end of each session, laser illumination ( $532 \mathrm{~nm}$ continuous illumination, $7.5 \mathrm{~mW}$ per hemisphere) was delivered for $10 \mathrm{~min}$ duration. In one group of rats, illumination occurred $0-10 \mathrm{~min}$ after cocaine infusion, whereas in the other group, illumination occurred 15-25 min after cocaine infusion. In one additional group of six rats, optical fibers were implanted into the RMTg as before, but no AAV was injected, serving as controls for light illumination alone. These animals were run identically to the second group above, i.e., during cocaine sessions optical fibers were mated to ferrules and illumination delivered at $7.5 \mathrm{~mW} /$ hemisphere $15-25 \mathrm{~min}$ after cocaine infusions.

In vitro brain slice preparation and recording. Animals were rapidly decapitated using a guillotine and their brains were removed and transferred to a beaker containing oxygenated $\left(95 \% \mathrm{O}_{2} / 5 \% \mathrm{CO}_{2}\right)$, ice-cold artificial CSF (aCSF) (in mм: 194 sucrose, $30 \mathrm{NaCl}, 4.5 \mathrm{KCl}, 1 \mathrm{MgCl}_{2}, 1.2$ $\mathrm{NaH}_{2} \mathrm{PO}_{4}, 10$ glucose, $26 \mathrm{NaHCO}_{3}$ ). The brain was then blocked to isolate the habenula before being glued onto the cutting stage of a vibrating tissue slicer (Leica, VT1000) and submersed in ice-cold, oxygenated aCSF. Four sagittal, or three coronal, slices $(280 \mu \mathrm{m})$ containing the habenula were obtained from each rat. The slices were transferred to an oxygenated holding chamber $\left(31^{\circ} \mathrm{C}\right.$ ) filled with normal aCSF (in mM: 126 $\mathrm{NaCl}, 3 \mathrm{KCl}, 1.5 \mathrm{MgCl}_{2}, 2.4 \mathrm{CaCl}_{2}, 1.2 \mathrm{NaH}_{2} \mathrm{PO}_{4}, 11$ glucose, 26 $\mathrm{NaHCO}_{3}$ ) and allowed to recover for at least $1 \mathrm{~h}$ before recording. All recorded membrane potentials were corrected for a $-12.2 \mathrm{mV}$ liquid junction potential.

One brain slice was transferred to a heated chamber $\left(31^{\circ}-33^{\circ} \mathrm{C}\right)$ and superfused with aCSF $(2 \mathrm{ml} / \mathrm{min})$ that was identical to that used for slice storage except for the addition of picrotoxin $(100 \mu \mathrm{M})$. Visualization of habenula neurons was performed with an upright microscope modified to provide a gradient contrast image using infrared illumination (Zeiss Axioskop), or a microscope equipped for epifluorescence and differential interference contrast (DIC) microscopy (BX51WI, Olympus). Recording electrodes $(\sim 5 \mathrm{M}[/ \mathrm{ohm}])$ were filled with (in $\mathrm{mM}): 140 \mathrm{~K}$-gluconate, $5 \mathrm{KCl}, 10$ HEPES, 0.2 EGTA, $2 \mathrm{MgCl}_{2}$, 4 Mg-ATP, $0.3 \mathrm{Na}_{2}$-GTP, 10 $\mathrm{Na}_{2}$-phosphocreatine, $0.125 \%$ biocytin, pH 7.2 with $\mathrm{KOH}$.

Whole-cell voltage and current-clamp recordings were performed using an Axopatch 200B amplifier (Molecular Devices). Cells were held at $-60 \mathrm{mV}$ during voltage-clamp recordings, and voltage steps and ramps were delivered using the Strathclyde electrophysiology software package (WCP, courtesy of Dr. John Dempster, Strathclyde University, Glasgow, UK; http://spider.science.strath.ac.uk/sipbs/ software_ses.htm) and an A/D board (ITC-18, Instrutech) residing in a personal computer. 
Picrotoxin, dopamine, and eticlopride were purchased from Sigma-Aldrich. Cocaine was obtained from NIDA Drug Supply and applied through bath superfusion using calibrated syringe pumps (Razel Scientific Instruments), while picrotoxin was included in the running buffer.

Stereotactic retrograde tracer injections for in vitro recordings. Male Sprague Dawley rats weighing 95-115 g were deeply anesthetized with an $80 \mathrm{mg} / \mathrm{kg}$ ketamine $(80 \mathrm{mg} / \mathrm{ml}) / x y l a z i n e ~(12 \mathrm{mg} / \mathrm{ml})$ solution (SigmaAldrich) and placed in a stereotaxic frame (Kopf Instruments). Two holes were drilled above the RMTg (anterior/posterior, $-5.0 \mathrm{~mm}$; mediolateral $0.9 \mathrm{~mm}$; dorsal/ventral, $-8 \mathrm{~mm}$ ). A sharp glass pipette ( $1 \mathrm{~mm}$ outer diameter, $0.25 \mathrm{~mm}$ inner diameter) was pulled using a vertical Narishige puller. The fine tip was then broken to a diameter of 25-50 $\mu \mathrm{m}$ and filled with Neuro-DiI (7\% in ethanol, Biotium) or CTB and slowly lowered into the RMTg. A Picospritzer III (ParkerHannifin) was used to pressure eject $\sim 150 \mathrm{nl}$ of dye. Pulses were delivered at $30-40$ psi for $5 \mathrm{~ms}$ every $20 \mathrm{~s}$ until the appropriate volume of dye was injected over a $5 \mathrm{~min}$ period. The electrode was left in place for an additional 5 min before being withdrawn $300 \mu \mathrm{m}$. It was again left in place for $3-5$ min before being completely withdrawn from the brain. Animals were allowed to recover 3-5 d before being killed for LHb recording. At the time of electrophysiological recording, epifluorescence microscopy was used to identify neurons in the LHb containing either CTB or Neuro-DiI that had been retrogradely transported from the injection site in the RMTg. Once a neuron was identified by fluorescence, DIC microscopy was used to record from the same neuron. All LHb neuron recordings in these experiments were made from animals in which retrograde tracer injections were confirmed to be in the RMTg during the dissection procedure.

Statistical analysis of electrophysiological and behavioral data. LHb neuron firing rates after intravenous drug injections were calculated in $5 \mathrm{~min}$ bins and normalized to the preinjection baseline. Units were discarded from further analysis if the SD of the spike amplitude exceeded $6 \%$ of the mean amplitude, as large fluctuations in amplitude could indicate drifting of the microwire electrodes during recordings. Firing rates were further averaged into an early period $(0-10 \mathrm{~min}$ postinjection) and a late period (15-35 min postinjection). During each period, we defined a neuron to be significantly inhibited (or excited) by cocaine if its firing rate was $>1.65$ SDs below (or above) baseline, corresponding to a onetailed $p$ value of 0.05 . The binomial theorem was then used to determine the likelihood that chance fluctuations would produce the observed number of inhibited (or excited) neurons. Data in most figures are represented by mean \pm SEM. However, runway latencies and retreats in several groups failed tests of normality (Shapiro-Wilks W test, $p<0.05$ ), and hence were analyzed using nonparametric tests, including the Kruskal-Wallis test, the Mann-Whitney $U$ test, and an ANOVA on ranktransformed data. Calculations were performed using Statistica 6.1 (StatSoft) or Prism v 5.01 software (Graph Pad).

\section{Results}

Cocaine induces biphasic inhibitory-excitatory responses in a subset of LHb neurons in awake behaving rats

Intravenous cocaine was previously shown to be rewarding immediately after injection, and aversive during a period starting 15 min after injection (Ettenberg et al., 1999; Knackstedt et al., 2002). To determine whether LHb firing rates after cocaine parallel these motivational shifts, we recorded from 31 neurons in the $\mathrm{LHb}$ vicinity in 10 rats receiving single doses of cocaine $(0.75$ $\mathrm{mg} / \mathrm{kg}$, i.v.). Histological reconstruction determined that 20 of these units resided within LHb boundaries and also met criteria for stability and isolation (Fig. 1C). The average baseline (i.e., preinfusion) firing rates of these neurons was $10 \pm 4 \mathrm{~Hz}$. During the period $0-10$ min after cocaine infusions, 13 of these $20 \mathrm{LHb}$ neurons were inhibited at least 1.73 SDs below their own baselines, a deviation that by chance should occur with probability 0.05 ( $t$ distribution, degrees of freedom $=19)($ Fig. $1 A, D)$. The proportion of inhibited neurons $(13 / 20=65 \%)$ was much larger
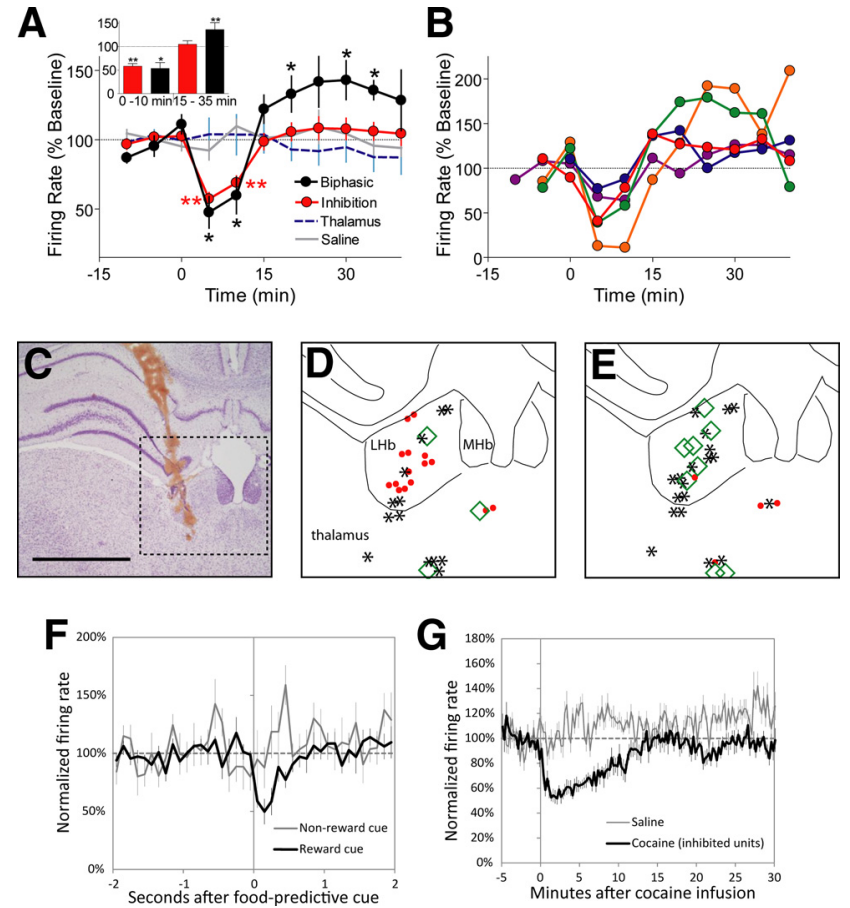

Figure 1. Lateral habenula ( $\mathrm{LHb}$ ) neurons show biphasic inhibitory-excitatory responses to cocaine. $\boldsymbol{A}$, Intravenous cocaine reduces LHb firing 0-10 min postinjection (red traces) and increases firing in a subpopulation of $L \mathrm{Hb}$ neurons $15-35$ min postinjection (black traces). Inset shows average firing rates during these two time windows of $\mathrm{LHb}$ neurons showing only inhibition, and those showing biphasic inhibition/excitation. Intravenous saline injections are without effect (gray trace), and there is no average change in firing rate among nearby thalamic neurons (blue trace). $\boldsymbol{B}$, Time course of responses of individual $\mathrm{LHb}$ neurons exhibiting biphasic responses to intravenous cocaine. $C$, Track along which neurons were recorded in one rat, shown against a Nissl counterstain. $\boldsymbol{D}$, Map of individual recorded neurons in the $\mathrm{LHb}$ and adjacent thalamus. During the period $0-10$ min postinjection, firing rates of neurons located within the LHb mostly show significant inhibition (red filled circles) or no change (asterisks) with only one neuron showing significant excitation (green filled circle). Neurons in the thalamus show equal proportions of inhibition versus excitation. $\boldsymbol{E}$, At 15-35 min postinjection, LHb neurons are either significantly excited (green diamonds) or nonresponsive (asterisks), with only one inhibition (red diamond). Notably, none of the recorded thalamic neurons showed the shift from inhibition to excitation seen in LHb neurons. F, G, Many LHb units show firing rate changes to both cocaine and food-predictive auditory cues. Each of these units exhibited an inhibitory response to the food cue (relative to a nonfood-predictive cue) $(\boldsymbol{F})$ and each neuron's response to cocaine was also inhibitory $(\boldsymbol{G})$. Data in $\boldsymbol{F}$ are plotted in $100 \mu$ s bins, whereas data in $\boldsymbol{G}$ are shown in $15 \mathrm{~s}$ bins. ${ }^{*} p<0.05$, two-tailed $t$ test; ${ }^{* *} p<0.02$, two-tailed $t$ test. Scale bar, $1 \mathrm{~mm}(\boldsymbol{C})$.

than the $5 \%$ expected by chance $\left(p=7 \times 10^{-13}\right.$, binomial distribution). During this same period, only $1 \mathrm{LHb}$ neuron was significantly excited, a number not higher than chance $(p=0.64$, binomial distribution), and the remaining 6 neurons showed no significant change from baseline. A much different pattern emerged during the period 15-35 min postinjection. Although most (13/20) LHb neurons returned to, or remained at, baseline firing during this time, seven showed significant deviations from baseline, and $86 \%$ of these neurons (6/7), representing $30 \%$ of all recorded $\mathrm{LHb}$ neurons, had firing rates at least $1.73 \mathrm{SDs}$ above their own baseline (Fig. 1A,B,E). Again, this is a much higher proportion than the $5 \%$ expected by chance $\left(p=3 \times 10^{-4}\right.$, binomial distribution). We recorded from an additional six $\mathrm{LHb}$ units after saline injections and saw no significant changes in firing rates in any neuron during either the early $(0-10 \mathrm{~min})$ or later (15-35 $\mathrm{min})$ time windows. The average firing rates of 11 nearby thalamic units were not affected by cocaine in either the earlier $(p=0.78)$ or later time windows $(p=0.4)$ (Fig. $1 A)$. 
Responses to two auditory cues predicting a food reward and absence of food reward were also examined in $12 \mathrm{LHb}$ units before cocaine administration. We found six neurons that showed significant acute responses to both cocaine and food-predictive cues, and in all six cases responses were inhibitory to both stimuli (Fig. $1 F, G$ ), indicating similar directions of responses to two very different positive motivational stimuli, consistent with prior reports that LHb neurons encode abstract motivational value.

\section{Prolonged biphasic $\mathrm{LHb}$ responses are seen in vitro after bath application of DA}

It is not known how cocaine influences LHb neuron firing rates, but the $\mathrm{LHb}$ receives a notable DA innervation directly from the anterior VTA (Gruber et al., 2007). To determine the possible role of DA on LHb firing, we used whole-cell voltage-clamp recordings in LHb brain slices. One prior study had noted that after brief inhibition $(\sim 1 \mathrm{~s})$, LHb neurons show rebound excitations lasting for tens of seconds (Chang and Kim, 2004), a duration too short to explain the prolonged excitations seen in our animals after cocaine in vivo. Hence, we examined whether more prolonged inhibition might produce longer rebound excitations. We found that approximately half of LHb neurons were hyperpolarized or exhibited associated inhibitory outward currents during DA application ( $\sim 2 \mathrm{~min}, 4 \mu \mathrm{M})$ (Fig. $2 A)$. We also found a population of LHb cells in which the inhibitory outward current caused by DA was followed by a delayed depolarizing inward current that occurred after DA application was terminated (Fig. $2 B$ ). In a group of 19 cells showing an initial hyperpolarizing outward current response to DA (mean outward current $86.3 \pm$ $14.7 \mathrm{pA}, n=8$ rats), 8 (42\%) also demonstrated significant inward depolarizing currents after DA application was terminated (Fig. 2B). These delayed inward currents persisted for at least 10-15 min after DA washout (Fig. 2B), similar to the durations of the delayed activations seen in vivo. In the remaining 11 cells (58\%), the outward (hyperpolarizing) holding currents returned to baseline after DA application was terminated, and no late inward component was observed (Fig. 2C), again consistent with in vivo recordings. To determine which receptors were involved in the DA response we recorded from a group of $\mathrm{LHb}$ neurons in which DA-induced outward currents could be observed, and then reapplied DA in the presence of the D2-like receptor antagonist eticlopride $(200 \mathrm{nM})$. We found that eticlopride prevented the DA-mediated outward current (Fig. 2C1,C2) $(\mathrm{DA}=23$ cells $/ 12$ rats, etic $+\mathrm{DA}=8$ cells $/ 15$ rats). Furthermore the selective D2-like agonist quinpirole ( $1 \mu \mathrm{M})$ mimicked the effect of DA in these cells (Fig. 2C1,C3). Similar experiments were conducted in LHb neurons during current-clamp recordings so that the effects of DA and the selective ligands could be measured on spontaneous firing rates. We found that DA $(4 \mu \mathrm{M})$ significantly reduced the mean firing rates of these cells ( $n=7$ cells/4 rats) (Fig. 2D1,D2) and that this was significantly prevented by eticlopride (200 nM) treatment ( $n=5$ cells/ 3 rats) (Fig. $2 D 1, D 2)$. In addition, quinpirole $(1 \mu \mathrm{M})$ also significantly reduced LHb neuron firing rates ( $n=15$ cells/ 7 rats) (Fig. $2 D 1, D 4)$ (one-way ANOVA, $F_{(3,77)}=20.41, p<0.0001$, pairwise comparisons with Bonferroni correction). Together, these data demonstrate that LHb neuron firing rates vary predictably with membrane current and that D2-like receptors mediate the inhibitory outward currents and inhibition of firing in these cells.

To determine whether $\mathrm{LHb}$ neurons exhibiting biphasic membrane currents projected to the RMTg we recorded from LHb neurons containing the fluorescent tracers CTB or NeuroDiI that had been retrogradely transported from the RMTg
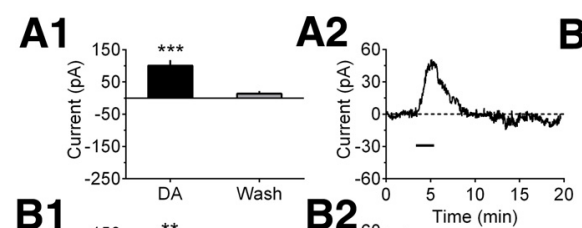

B3 $^{\text {a. }(6 \mathrm{~Hz})}$
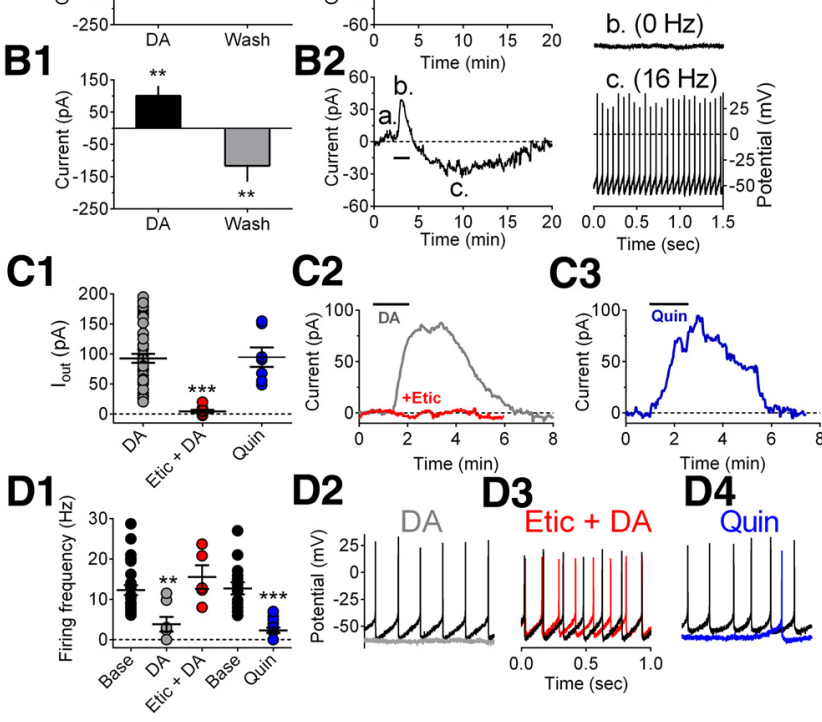

Figure 2. Effects of DA on LHb neurons in vitro. $\boldsymbol{A} 1$, Mean ( $n=11$ cells) dopamine-induced change in holding current (Current) in a subset of LHb neurons in brain slices. A significant outward (hyperpolarizing) current is observed when dopamine (4 $\mu \mathrm{M})$ is applied to the LHbcontaining brain slices, followed by a return to baseline during washout. $\boldsymbol{A 2}$, Time course of the effect of dopamine (black horizontal bar) in a single $\mathrm{LHb}$ neuron in which only an inhibitory outward current was observed. $\mathbf{B 1}$, Mean ( $n=8$ cells) dopamine-induced change in holding current in another subset of $\mathrm{LHb}$ neurons (biphasic cells) in which inhibitory outward currents were followed by depolarizing inward currents during dopamine washout. B2, A typical time course of the membrane current of a biphasic $\mathrm{LHb}$ neuron demonstrating a biphasic response to dopamine. Note the longer lasting delayed inward current following cessation of dopamine application (black horizontal bar). B3, Traces showing spontaneous action potential discharge for the cell shown in $\boldsymbol{B 2}$. Each trace $(\boldsymbol{a}-\boldsymbol{c})$ was recorded during the corresponding labeled period shown in B2. Dopamine hyperpolarized this cell and eliminated spontaneous firing, followed by an increase in firing rate above baseline during washout. $C_{1}$, Mean DA agonist-induced inhibitory outward currents. Peak current amplitude for each cell tested under each of the indicated conditions is shown as well as the mean \pm SEM for all cells (superimposed horizontal bars). C2, Example of the effect of DA $(4 \mu \mathrm{m})$ on membrane current in a single $\mathrm{LHb}$ neuron, and its blockade by the D2 antagonist eticlopride (Etic, $200 \mathrm{~nm}$ ). C3, Effect of the D2-like DA receptor agonist quinpirole (Quin, $1 \mu \mathrm{M}$ ) on membrane current in another LHb neuron. Note that the effects of DA were blocked by eticlopride and mimicked by quinpirole, indicating D2-like receptor involvement in the inhibition of $\mathrm{LHb}$ neurons. Etic alone had no effect on membrane current (data not shown).D1, Mean effects of DA (4 $\mu \mathrm{M})$, Quin (1 $\mu \mathrm{M})$, and Etic ( $200 \mathrm{~nm}$ ) on spontaneous firing of $L H b$ neurons. D2, Example of the effect of DA (gray trace) on firing in a single $L H b$ neuron. D3, The effect of DA on cell firing is blocked by Etic (red trace) in the same cell shown in D2.D4, Effect of Quin (blue trace) on spontaneous firing in a single LHb neuron. In D2-D4, black traces correspond to baseline immediately before drug application. ${ }^{* *} p<0.001$, ${ }^{* * *} p<$ 0.0001 , one-way ANOVA and Bonferroni post hoc test with multiple-comparison correction.

( $n=4$ rats). Similar to the experiments described above in unlabeled LHb neurons, we observed biphasic responses to DA in 2/8 fluorescently labeled LHb neurons that project to the RMTg (data not shown).

\section{Cocaine effects on $\mathrm{LHb}$ neurons in vitro}

To determine whether cocaine alters LHb neuron activity in vitro and whether this is mediated by endogenous DA in this region, we examined the effects of bath-applied cocaine on LHb neurons in brain slices. Similar to the effects of exogenous DA described above, bath-applied cocaine at a concentration $(10 \mu \mathrm{M})$ similar to that present in vivo during drug self-administration (Zimmer et al., 2011) initiated outward currents in LHb neurons $(n=13$ 

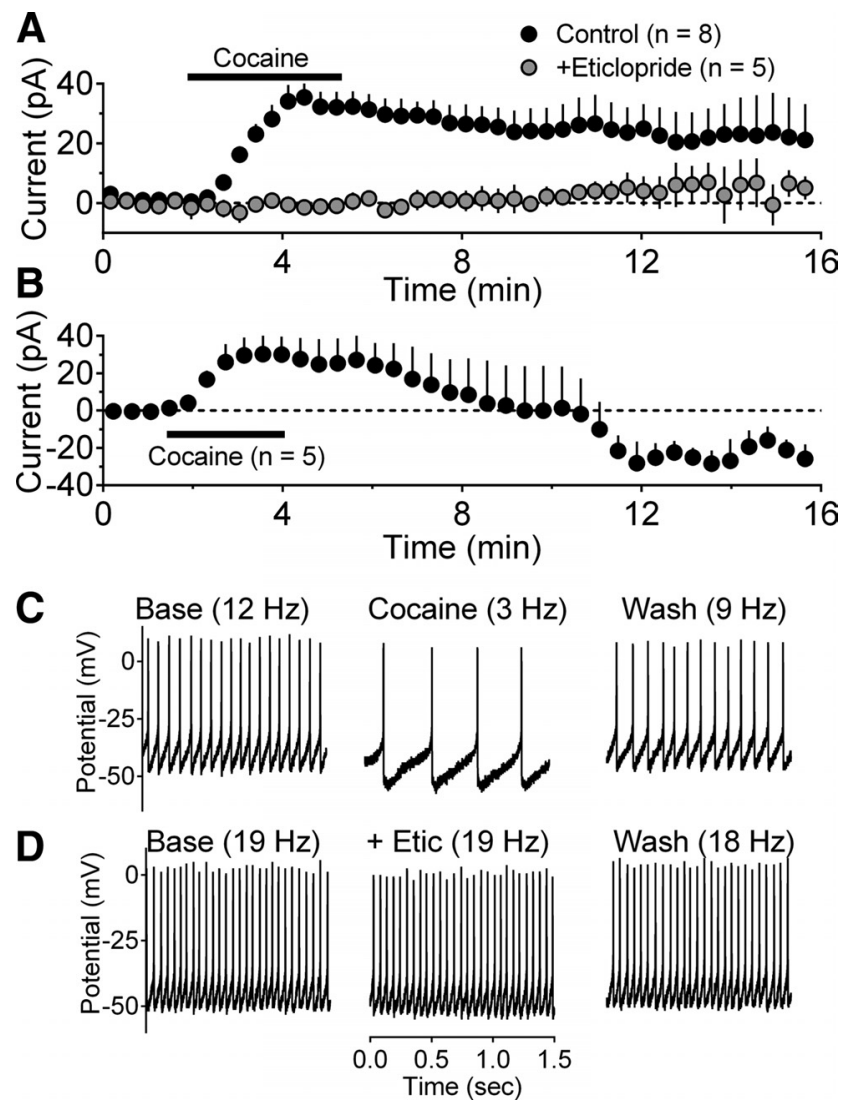

Figure 3. Cocaine effects on LHb neurons in vitro. $A$, Mean ( \pm SEM) time course of cocaine $(10 \mu \mathrm{M})$-induced changes in neuron membrane current in a group of cells demonstrating only inhibitory outward currents, and blockade by the DA D2-like receptor antagonist eticlopride (200 nm). B, Mean time course of membrane current in five neurons demonstrating biphasic responses to cocaine. $C$, Representative current-clamp recordings of membrane responses from $\mathrm{LHb}$ neuron during cocaine $(10 \mu \mathrm{M})$ application. Cocaine hyperpolarized this neuron and decreased the rate spontaneous action potential discharge. A similar action of cocaine was observed in another $\mathrm{LHb}$ neuron. $\boldsymbol{D}$, Representative blockade of the inhibitory effect of cocaine on spontaneous firing by eticlopride ( $200 \mathrm{~nm}$ ) in LHb neuron. These data and the ability of eticlopride to block the inhibitory effects of DA on LHb neuron firing (Fig. 2D) suggest that these effects are mediated by D2-like DA receptors. The term "Base" refers to recordings made during a stable baseline period.

cells/8 rats; $33.8 \pm 5.0 \mathrm{pA}$ ) (Fig. $3 A$ ). Like the effect of DA, the inhibitory outward currents produced by cocaine were blocked by the D2-like receptor antagonist eticlopride (200 nM) (Fig. 3A). Also similar to the effects of DA shown in Figure 2, the inhibitory effect of cocaine could hyperpolarize LHb neurons and reduce spontaneous firing (Fig. $3 C)(n=2$ cells/2 rats). Furthermore, this inhibitory effect of cocaine could be blocked by eticlopride (Fig. 3D).

Five of the 13 cells $(38 \%)$ in which cocaine was tested also exhibited persistent inward currents following the outward currents after cocaine application was terminated (Fig. $3 B$ ). This biphasic response to cocaine in these LHb neurons was therefore observed in similar proportion to that seen following DA application in vitro and in the recordings from behaving animals. Outward holding current changes that were seen in the remaining 8 cells $(62 \%)$ from this group returned to baseline after cocaine washout (Fig. $3 A, C$ ).

Cocaine-activated $\mathrm{LHb}$ neurons preferentially project to the RMTg and influence its activation

Consistent with our finding of increased firing rates in some LHb neurons after cocaine, prior studies also found increased c-Fos in the LHb after cocaine (Zahm et al., 2010). To determine whether these c-Fos activated LHb neurons project to the RMTg, we injected two groups of rats ( $n=5$ each group) with the retrograde tracer CTB into either the RMTg (Fig. 4A) or VTA (Fig. 4B), followed 6-12 d later by an injection of cocaine $(10 \mathrm{mg} / \mathrm{kg}$, i.p.) $1 \mathrm{~h}$ before kill. In the LHb, both groups exhibited similar overall numbers of c-Fos-immunoreactive neurons (average $31 \pm 6$ and $38 \pm 12$ cells/section, $p=0.7)$ and similar numbers of overall retrogradely labeled LHb neurons $(50 \pm 11$ and $65 \pm 27$ cells/ section, $p=0.6)$. However, in RMTg-injected rats, $34 \pm 8 \%$ of $\mathrm{LHb}$ retrogradely labeled neurons expressed c-Fos (Fig. 4C,I), comparable to the percentage of rebounding neurons observed electrophysiologically, whereas in rats with tracer injections into the VTA, only $4 \pm 2 \%$ of CTB-labeled neurons exhibited c-Fos activation, a significantly lower proportion $(p=0.005)$ (Fig. $4 D, I)$.

Because the majority of LHb neurons are glutamatergic, we hypothesized that cocaine-induced $\mathrm{LHb}$ activation contributes to cocaine-induced c-Fos in the RMTg. Hence, in five rats we unilaterally lesioned the posterior LHb and adjacent FR, a preferentially ipsilateral pathway that carries almost all LHb projections to the RMTg (Jhou et al., 2009a) (Fig. 4E). These rats later received a single cocaine injection ( $10 \mathrm{mg} / \mathrm{kg}$, i.p.) $1 \mathrm{~h}$ before kill; brains were then stained for c-Fos and the neuronal marker NeuN. We found no differences in total NeuN-labeled RMTg neurons between intact and lesioned hemispheres ( $68 \pm 7$ and $74 \pm 6$ cells/ section, respectively, $p=0.63$ ), indicating that LHb/FR lesions did not cause degeneration of downstream targets in the RMTg. However, $58 \pm 4 \%$ of NeuN-positive RMTg neurons in the contralateral (intact) hemisphere were c-Fos-immunoreactive (Fig. $4 H$ ), versus only $28 \pm 4 \%$ in the ipsilateral (lesioned) hemisphere, a twofold reduction $(p=0.002)$ (Fig. $4 G, J)$. In contrast, c-Fos expression in VTA neurons did not differ between lesioned and intact hemispheres $(10 \pm 3 \%$ and $9 \pm 2 \%$ of NeuN-positive neurons, respectively, $p=0.79$ ). Hence, RMTg activation by cocaine appears to be significantly driven by cocaine-activated habenular afferents, whereas habenular projections to the VTA appear to comprise a functionally separate circuit that does not exhibit cocaine-induced c-Fos. The existence of parallel distinct $\mathrm{LHb}$ output pathways having different responses to cocaine is consistent with at least one prior report (Maroteaux and Mameli, 2012).

\section{Behavioral influences of the $\mathrm{LHb} \rightarrow \mathrm{RMTg}$ circuit}

Prior studies had noted that intravenous cocaine can produce either conditioned place preference or place aversion depending on whether animals are placed into conditioning chambers 0 or 15 min postinjection (Ettenberg et al., 1999). We attempted to replicate these findings, while also examining conditioning at 30 min postinjection. Three groups of rats receiving cocaine $(0.75$ $\mathrm{mg} / \mathrm{kg}$, i.v.) 0,15 , or $30 \mathrm{~min}$ before CPP conditioning sessions ( $n=5,12$, and 8 , respectively) showed no significant preferences for either chamber during the baseline trials $(p>0.2)$. Rats receiving cocaine immediately before placement into chambers showed strong place preference (preference score $=102 \pm 26 \mathrm{~s}$, $n=5, p=0.009$, one-tailed $t$ test), whereas rats receiving cocaine 15 min prior showed mild aversion (preference score $=-46 \pm$ $23 \mathrm{~s}, n=12, p=0.029$, one-tailed $t$ test). Although the latter effect did not remain significant after a Sidak-Bonferroni correction for experiment-wide error (which requires $p<0.0127$ for an overall error rate of 0.05 ) (Fig. $4 K$ ), its magnitude is comparable to multiple prior reports, indicating repeatability and consistency across experiments and laboratories (Etten- 
A

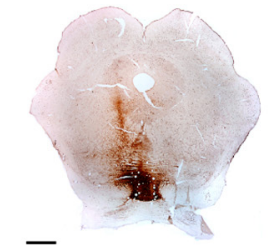

B
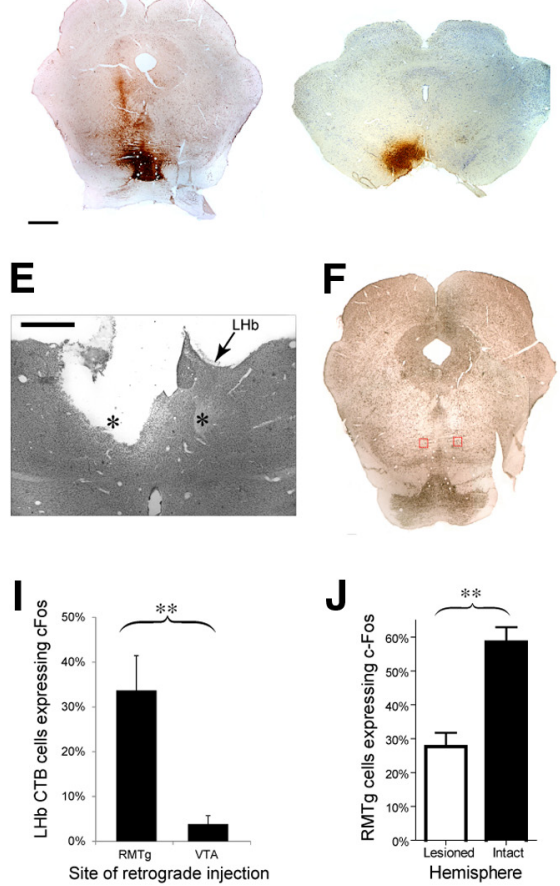

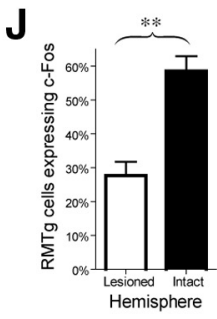

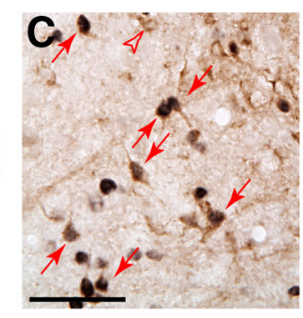
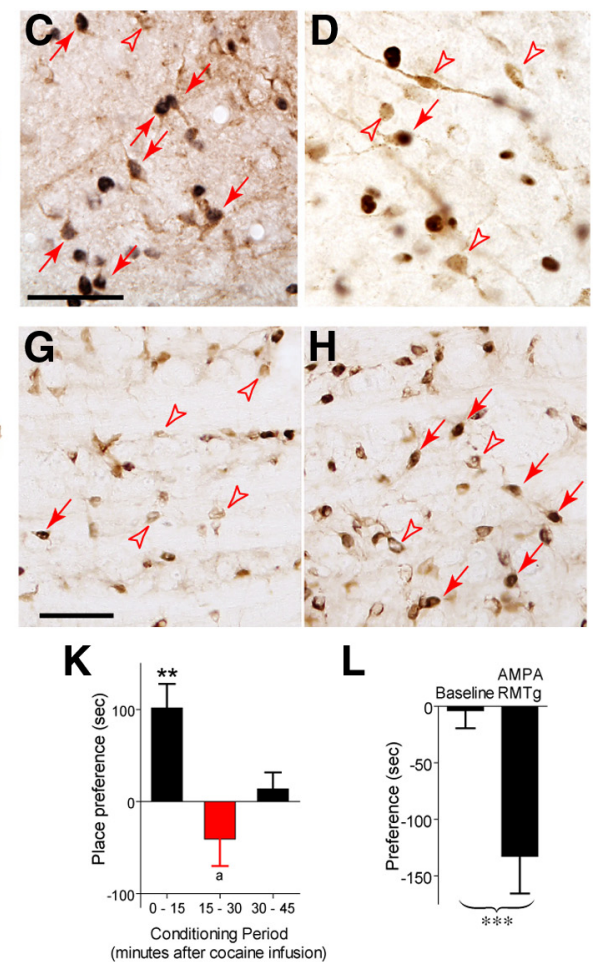

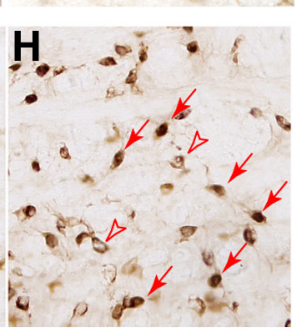

$\mathbf{L}$

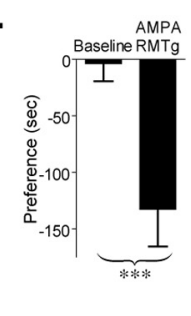

Figure 4. Functional linkage of $\mathrm{LHb}$ and RMTg. We examined C-Fos in $\mathrm{LHb}$ neurons that were labeled by retrograde tracer injections into either the RMTg (A, site also spread to IPN) or VTA (B). Cocaine-induced c-Fos was found in $37 \pm 9 \%$ of RMTgprojecting LHb neurons $(\boldsymbol{C})$, but in a much lower percentage of VTA-projecting LHb neurons $(\boldsymbol{D})$. Black label indicates C-Fos immunoreactivity; brown label indicates retrograde tracer immunoreactivity. Red filled arrows indicate neurons expressing both tracer and c-Fos, whereas open arrows indicate neurons expressing tracer only. Unilateral lesions of the posterior LHb and fasciculus retroflexus ( $F R$, indicated by asterisk) $(\boldsymbol{E})$, produce a twofold reduction in cocaine-induced c-Fos in the ipsilateral (lesioned) RMTg $(\boldsymbol{G})$ relative to the contralateral (intact) RMTg $(\boldsymbol{H})$, suggesting that cocaine-induced RMTg c-Fos is partly dependent on its LHb afferents. $\boldsymbol{G}, \boldsymbol{H}$ Magnified from left and right boxed regions in $\boldsymbol{F}$, where brown cytoplasmic label indicates immunoreactivity for the neuronal marker NeuN. Red filled arrows indicate neurons immunoreactive for both NeuN and c-Fos, whereas open arrows indicate cells expressing NeuN alone. Graphs show percentages of cocaine-induced double-labeled neurons in the LHb after retrograde tracer injections $(\boldsymbol{I})$ or $\mathrm{LHb} / \mathrm{FR}$ lesions $(\boldsymbol{J})$. $\boldsymbol{K}$, Animals show conditioned place aversion if placed into conditioning chambers $15 \mathrm{~min}$ after intravenous cocaine infusions, whereas placement 0 min postinfusion produces place preference, and placement 30 min postinfusion produces neither preference nor aversion. $L$, Activation of the RMTg by local AMPA injections produces conditioned place aversion. Scale bars, $\boldsymbol{A}, \boldsymbol{B}, \boldsymbol{E}, \boldsymbol{F}, 1 \mathrm{~mm} ; \boldsymbol{C}, \boldsymbol{D}, \boldsymbol{G}, \boldsymbol{H}, 50 \mu \mathrm{m} .{ }^{* *} p<0.01,{ }^{* * *} p<0.001,{ }^{\mathrm{a}} p<0.05$, one-tailed.

berg, 2004; Ettenberg and Bernardi, 2007). When cocaine was given $30 \mathrm{~min}$ before placement into chambers, animals showed neither preference nor aversion (preference score $=14 \pm 18 \mathrm{~s}$, $n=8, p=0.46$, two-tailed $t$ test) (Fig. $4 K$ ). The temporal relationship between the rewarding or aversive effects of cocaine and the biphasic responses of LHb neurons suggests that habenulomesencephalic activation might drive conditioned aversive effects of cocaine. Indeed, prior studies had noted that activation of glutamatergic $\mathrm{LHb}$ projections to the RMTg region induces conditioned place aversion (Stamatakis and Stuber, 2012), consistent with our own findings that AMPA agonist injections (0.3 $\mathrm{mM}, 300 \mathrm{nl}$ ) into the RMTg produce robust conditioned place aversion (preference score before and after conditioning, $-6 \pm$ $20 \mathrm{~s}$, and $-129 \pm 37 \mathrm{~s}$, respectively, $n=5, p=1.3 \times 10^{-4}$, paired $t$ test) (Fig. $4 L$ ).

To test whether the LHb and RMTg contribute to the conditioned aversive effects of cocaine, we used a runway operant paradigm particularly suited for examining conflicting rewarding and aversive conditioning (Ettenberg and Geist, 1993; Geist and Ettenberg, 1997). Prior studies found that animals traversing a runway daily to self-administer intravenous cocaine demonstrate progressively longer latencies to reach the goal compartment, as

well as increased alternation between approach and retreat, reflecting a mixture of learned approach and avoidance responses to cocaine (Geist and Ettenberg, 1997). We examined whether these running patterns would be affected by lesions of the FR or RMTg, or by temporally specific optogenetic inhibition of the RMTg 15-25 min after reaching the goal compartment, when cocaine-induced LHb excitations are prominent.

For the lesion experiments, we tested four groups of rats: the first group received an intravenous catheterization and no other surgery ( $n=6$, uninjected controls), whereas the second group also received a saline injection into the RMTg ( $n=5$, sham-injected controls) (Fig. $5 A, C)$, the third received excitotoxin injections into the RMTg $(n=5)$ (Fig. $5 B)$ and the fourth received an electrolytic lesion of the FR $(n=6)$ (Fig. $5 D)$. Each rat received 2-4 training trials in which 180 mg of food pellets were placed in the goal box, followed by seven trials in which only cocaine was delivered $(0.75 \mathrm{mg} / \mathrm{kg}$, i.v. $)$ upon reaching the goal box. Latencies to reach the goal box did not differ between groups during food trials $(p=0.73$, Kruskal-Wallis). During the first cocaine trial, when rats were still guided by their previous experience with food, median latencies ranged from 19 to $29 \mathrm{~s}$, and also did not differ between groups $(p=0.37$, Kruskal-Wallis). The two control groups (uninjected and sham-injected) showed large and nearly identical increases in median latencies to reach the goal box during trials 4-7 (461 and 535 s, respectively, $p=$ 1.0, Mann-Whitney) and also showed nearly identically large numbers of run reversals during trials $4-7$ (20.25 and 19.75 reversals, $p=0.7$ Man$\mathrm{n}$-Whitney). Because of their similarity, these two control groups were combined into a single control group for subsequent statistical analyses. Nonparametric statistical tests were used for all runway tests as run latency and reversal distributions were significantly non-normal ( $p<0.05$, Shapiro-Wilks test on ANOVA residuals).

Using a repeated-measures ANOVA on rank-transformed latency data, we noted a significant effect of lesion group $(p=$ 0.001 ), trial group (trial 1 vs trials $4-7, p=0.003$ ), and group $\times$ trial interaction $(p=0.05)$, indicating that run latencies evolved differently over time between groups. Post hoc pairwise comparisons showed that only unlesioned rats exhibited an increase in median run latencies or reversals over time $(p=0.0009$ and 0.0002 respectively, Tukey HSD comparison of trial 1 vs trials $4-7$ ) (Fig. $6 A-D$ ). Hence, lesions of either the RMTg or LHb prevented development of conditioned avoidance of the goal compartment. Post hoc tests did not find any differences between RMTg-lesioned and FR-lesioned rats, suggesting that both types of lesions influenced behavior equally effectively. Plots of the run pattern for individual animals showed a striking tendency for 


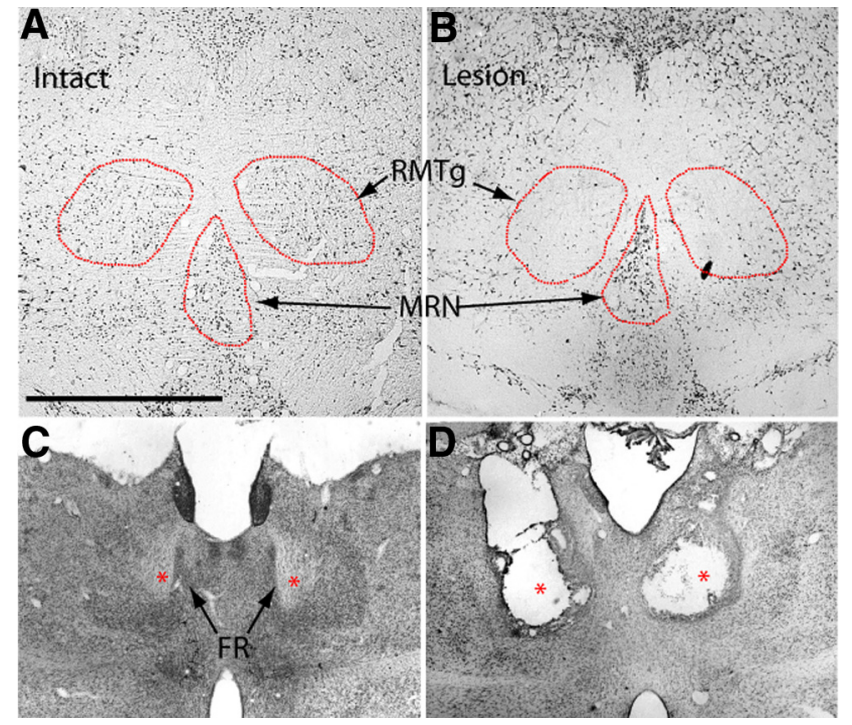

Figure 5. Histological confirmation of lesions of the RMTg and FR. $A, B$, The fiber-sparing excitotoxin quinolinic acid ablates the RMTg region while relatively sparing neurons in the adjacent MRN, as determined by NeuN immunostaining. C, Nissl-stained sections showing intact FR (asterisks). $\boldsymbol{D}$, Nissl-stained brain section after bilateral electrolytic FR lesion (asterisks). Scale bars: $\boldsymbol{A}, \boldsymbol{B}, 1 \mathrm{~mm} ; \boldsymbol{C}, \boldsymbol{D}, 2 \mathrm{~mm}$.

unlesioned rats to approach and retreat repeatedly from the goal box without entering it, whereas lesioned rats did not exhibit this behavior (Fig. 6E,F).

\section{Behavioral effects of temporally specific post-cocaine RMTg inhibition}

Because FR and RMTg lesions were made before behavioral testing, we cannot distinguish whether they affect learning or performance of runway behavior, nor whether habenulomesencephalic activation is particularly critical during the time window when $\mathrm{LHb}$ activation is prominent. Hence, we used an optogenetic method to inhibit RMTg activity at selected phases after cocaine infusion. Twenty-two animals received injections into the RMTg of AAV containing ArchT, a light-activated hyperpolarizing proton pump (Fig. 7A). After 2-3 weeks of recovery, efficacy of opsin expression was determined by measuring light-induced $(532 \mathrm{~nm}$, $7.5 \mathrm{~mW}$ constant illumination each side) disinhibition of locomotor distance traveled during a simple Pavlovian approach task (Fig. $7 \mathrm{~B}, \mathrm{C}$ ). In this test, 60 s illumination periods were alternated with $60 \mathrm{~s}$ of nonillumination for a single 32 min test. In 13 animals, optical fibers and virus injections resided within $500 \mu \mathrm{m}$ of the RMTg center, and in these animals, average locomotor distance traveled was $62 \pm 8 \%$ higher during light-on epochs than light-off epochs, a significant increase $\left(p=1.6 \times 10^{-6}\right)$. In contrast, in 4 animals where fibers and virus were placed $500-600$ $\mu \mathrm{m}$ dorsal to the RMTg, average locomotion was only $3 \pm 4 \%$ higher during light-on epochs than light-off, a nonsignificant difference $(p=0.52)$. An additional six rats received optical fiber implants directed at the RMTg, but no AAV injections, and served as controls for any effects of light/heat application alone. These rats did not show significant effects of illumination on locomotion either individually or as a group.

$\mathrm{AAV}$-injected rats were assigned randomly to one of two groups for runway testing. One group, designated the "early inactivation" group $(n=6)$, received light-induced (532 nm, 7.5 $\mathrm{mW}$ each hemisphere) inhibition of the RMTg 0-10 min after cocaine injections, when cocaine is rewarding and when $\mathrm{LHb}$
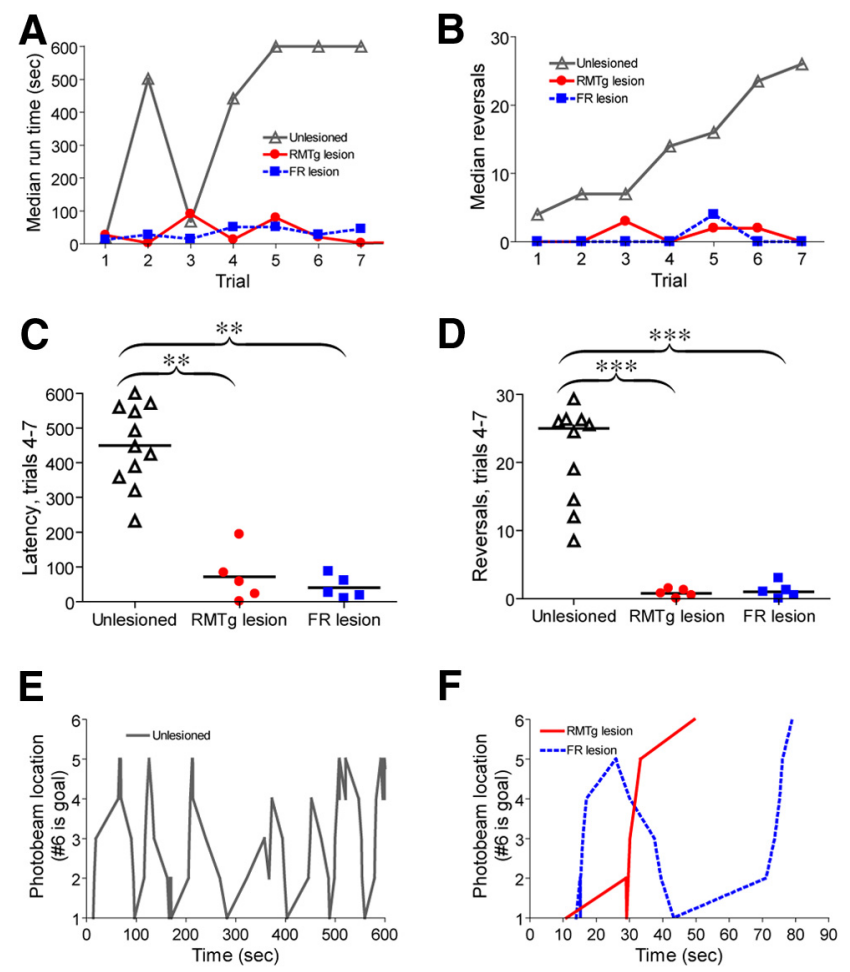

Figure 6. $\quad \mathrm{LHb}$ and RMTg role in conditioned avoidance responses to cocaine. $\boldsymbol{A}$, Unlesioned animals traversing a runway to obtain cocaine show progressive increases in run latencies (open triangles) reflecting conditioned avoidance of the cocaine-paired goal compartment. Animals with FR or RMTg lesions show no such increase (filled round and square symbols), suggesting a failure to develop conditioned avoidance. $\boldsymbol{B}$, Unlesioned animals show progressive increases in alternations between approach and retreat, thought to reflect conflicting rewarding and aversive effects of cocaine, whereas FR or RMTg-lesioned animals lack this increase in reversals. Latencies and reversals are shown as medians for each trial. Scatterplots show latencies $(\boldsymbol{C})$ and reversals $(\boldsymbol{D})$ averaged over trials $4-7$ for each individual rat; horizontal lines represent group medians. $\boldsymbol{E}$, Representative path traversed by an individual unlesioned rat alternates between approach and retreat, whereas rats with $L$ Hb or RMTg lesions $(\boldsymbol{F})$ show markedly fewer reversals and much faster latencies. Note large difference in time scales between $\boldsymbol{E}$ and $\boldsymbol{F}$. ${ }^{* *} p<0.01$, ${ }^{* * *} p<0.002$.

neurons show reduced firing rates, whereas the second group, designated the "late inactivation" group $(n=7)$, received lightinduced RMTg inhibition 15-25 min after cocaine injections, when LHb activation is prominent. An additional six rats received only optical fiber implants; this "no-virus" group was tested in the same manner as the late-inactivation group.

Run latency data were analyzed similarly to the lesion experiment, with median latencies over trials 4-7 compared with the latency from trial 1. A two-way repeated-measures ANOVA on rank-transformed latency data showed significant effects of the animal group ( $p=0.017)$ and trial group (i.e., the repeated measure, trial 1 vs trials $4-7, p=0.0001$ ), as well as a significant group $\times$ trial interaction $(p=0.009)$ indicating that latencies evolved differently over time between the three groups. Post hoc testing of all pairwise comparisons (Tukey HSD test) showed results consistent with our hypothesis. As expected, none of the three groups differed from each other in run latency on trial 1. The no-virus and early inhibition groups showed significant increases in run latency from trial 1 to trials $4-7$ ( $p=0.0015$ and 0.002 , respectively, Tukey HSD), whereas the late-inhibition group did not ( $p=0.95$, Tukey HSD). Hence, ArchT-mediated RMTg inhibition 15-25 min post-cocaine blocked the emergence of avoidance behavior, unlike optical illumination at an earlier 
A

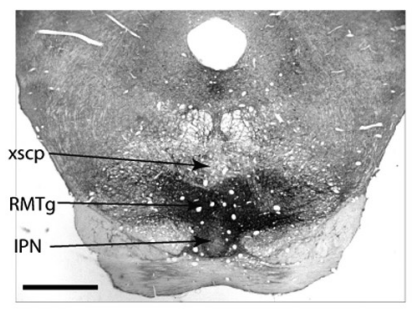

D
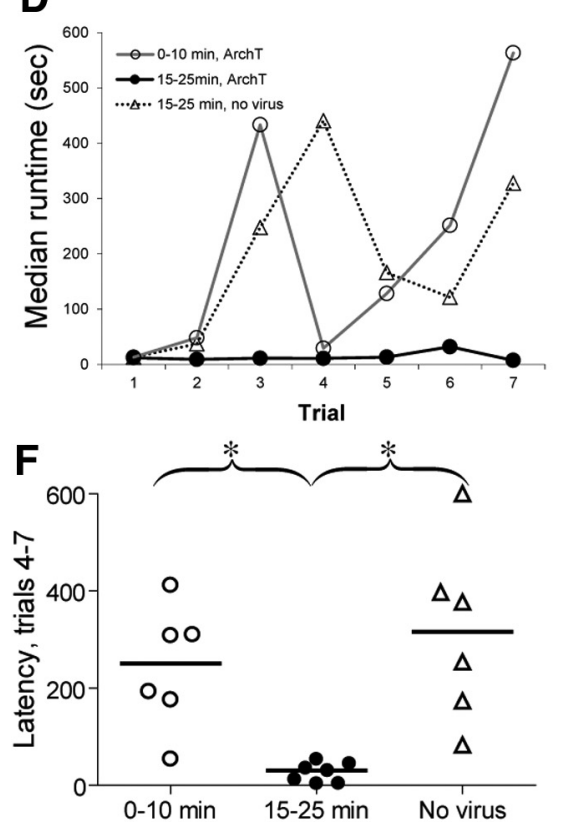

B

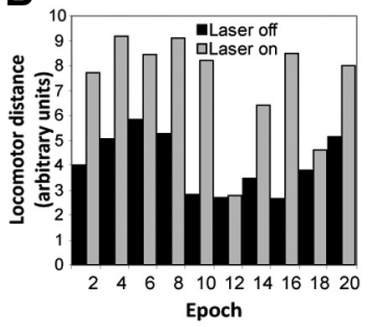

E

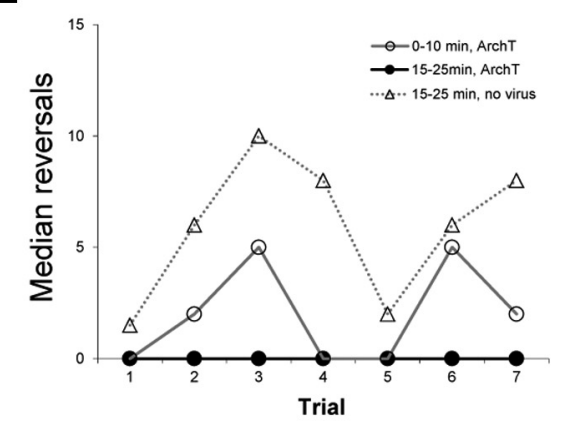

G

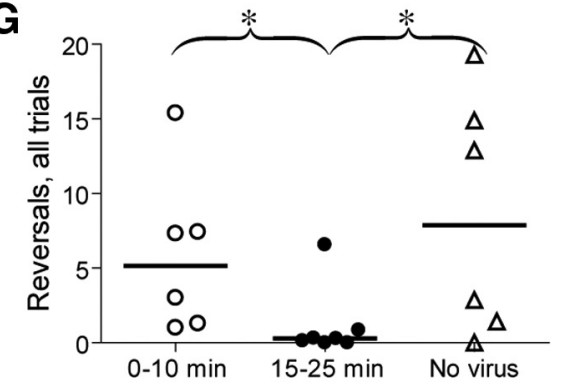

Figure 7. Optogenetic characterization of RMTg role in conditioned avoidance response to cocaine. $\boldsymbol{A}$, We tested behavioral effects of optical inhibition of RMTg area neurons after injections of AAV containing the light-sensitive proton pump ArchT. Virus also expresses GFP, indicated by dark immunoreactivity in RMTg region dorsal to the IPN and ventral to the decussation of the superior cerebellar peduncle (xscp). Optical fibers in this case are in the RMTg, but slightly rostral to the plane shown. $B$, Efficacy of ArchT expression is assessed by measuring locomotor distance traveled (in arbitrary units), while optogenetic inhibition of RMTg is applied during alternate 60 s epochs, producing repeatable and reversible increases in distance traveled. C, Graph showing ratio of distance traveled in even versus odd (light-on v light-off) epochs; this ratio is significantly higher than 1.0 when virus and fiber are in the RMTg, but not when virus and fibers are located $0.6 \mathrm{~mm}$ dorsal. $\boldsymbol{D}$, Animals receiving optogenetic inhibition of the RMTg 0-10 min after cocaine infusions showed progressive increases in run latencies, similarly to sham control rats and to animals receiving optical illumination without inhibitory opsins present. In contrast, animals expressing ArchT and receiving optical inhibition 15-25 min postinfusion did not show increased run latencies, suggesting that neural activation of the RMTg during the $15-25 \mathrm{~min}$ window after cocaine is critically required for conditioned avoidance behaviors. Notably, optical illumination is only delivered after animals reach the goal compartment and receive cocaine; hence, observed run patterns are presumably influenced by optical illumination that occurred during preceding trials. $\boldsymbol{E}$, Optogenetic inhibition of the RMTg $15-25$ min postdrug also reduced run direction reversals relative to the other two groups. $\boldsymbol{F}, \boldsymbol{G}$, Scatterplot of average latencies $(\boldsymbol{F})$ and reversals $(\boldsymbol{G})$ averaged over trials $4-7$ for each individual rat. Horizontal lines are group medians. Scale bar, $\boldsymbol{A}, 1 \mathrm{~mm} .{ }^{*} p<0.05,{ }^{* *} p<$ 0.00001 .

time window or illumination without ArchT expression (Fig. $7 D, F)$.

Reversal data in our optogenetic experiment was somewhat compromised by the increased turning torque from bilateral fiberoptic cables for delivering laser illumination, making it noticeably more difficult for rats to change running direction. Due to the low number of reversals in all groups, and hence reduced statistical power, we did not partition reversal data by trial, and only compared median reversals over all trials. A nonparametric ANOVA (Kruskal-Wallis) found a significant difference in reversals between groups $(p=0.024)$, and post hoc pairwise tests revealed that the late inhibition group had fewer reversals than the no-virus group $(p=0.04)$, again indicating that ArchT-mediated inhibition of the RMTg 15-25 min post-cocaine, but not optical

illumination alone, prevented the emergence of cocaine avoidance behavior (Fig. $7 E, G)$.

\section{Discussion}

We found that in behaving rats, LHb neurons predominantly exhibit initial inhibitory responses to cocaine followed by a delayed excitation in a subset of neurons that temporally parallels cocaine's shift from appetitive to aversive. Results from $\mathrm{LHb}$ neurons in brain slices corroborated this pattern of cellular activity, and further demonstrated that the biphasic responses are present in RMTg-projecting LHb neurons and are likely influenced by DA receptors within the LHb. c-Fos studies then provided evidence that $\mathrm{LHb}$ neurons projecting to the RMTg are particularly likely to show cocaine-induced c-Fos, and causally contribute to RMTg activation. Finally, a series of behavioral experiments demonstrated that activation of the RMTg (by AMPA) is sufficient to produce aversive conditioning, while cocaine-conditioned avoidance responses are abolished by lesions of the FR or RMTg, or by inhibition of RMTg activity 15-25 min after cocaine delivery, when LHb neurons are excited. Together with prior studies of DA/LHb/RMTg interactions, the present findings indicate that DA actions in the habenulomesencephalic system (Fig. 7) play fundamental roles in several types of opponent interactions between rewarding and aversive brain processes.

\section{Methodological issues}

One key experiment involved placement of optical fibers and AAV into the RMTg. Although the exact amount of light and virus spread is difficult to quantify, it is notable that our locomotor disinhibition test showed very different effects of optogenetic inhibition centered in the RMTg, versus inhibition centered 500-600 $\mu \mathrm{m}$ dorsally. Hence, we believe that optogenetic effects are at least limited to this radius. However, some structures, most notably the median raphe nucleus (MRN) and interpeduncular nucleus (IPN), do reside at least partly within $500 \mu \mathrm{m}$ of the RMTg, and receive habenula innervation. Hence, we cannot conclusively rule out involvement of these structures, although several arguments suggest these are less likely candidates. First, the IPN and MRN extend substantially ventral or caudal to the RMTg, respectively, and our optogenetic manipulations likely influenced only a fraction of either region. Second, several of our RMTg-targeted optical fibers resided relatively rostrally in the RMTg, where the MRN structure is absent. Finally, excitotoxic RMTg lesions in our lesion experiment largely avoided the IPN and MRN, indicating that the latter regions do not need to be compromised to influence behavior (although this does not rule out that multiple regions could be influential). 


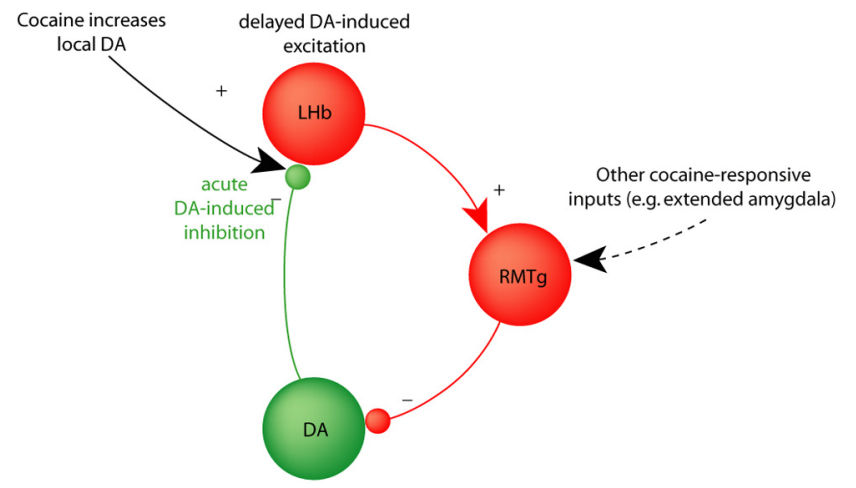

Figure 8. Schematic of feedback loops between LHb, RMTg, and VTA DA neurons. In this proposed circuit model, cocaine increases DA levels in the LHb, initially inhibiting LHb neurons (red) and contributing to reciprocally inhibitory interactions between DA and LHb neurons. DA-induced delayed excitation of the LHb (black text and arrow) converges with cocaineinduced responses in other RMTg afferents to drive a negative feedback signal opposing the initial actions of cocaine and other DA-mediated rewards.

One other methodological issue is the use of intraperitoneal injections to assess c-Fos in the LHb and RMTg, whereas intravenous injections were used in our other experiments. In pilot experiments from two animals, we noted that intraperitoneal cocaine injections elicit biphasic responses in $\mathrm{LHb}$ firing rates that are qualitatively similar to intravenous injections, albeit possibly with a slightly slower time course (T. C. Jhou, unpublished observations). Although preliminary, these results suggest that these different routes of administration may produce similar patterns of LHb activation. Finally, it should be noted that the noncontingent delivery of cocaine examined in current recording and CPP studies might induce aversive responses in a different manner or degree than voluntary intake in self-administration studies (Mutschler and Miczek, 1998)—this question would need to be addressed in future studies.

\section{A network of brain regions driving cocaine-conditioned avoidance behavior}

Our results show that pronounced LHb activation in vivo peaked $\sim 15$ min after cocaine injections, when plasma levels of cocaine are at least an order of magnitude below initial levels after intravenous injections (Booze et al., 1997; Ma et al., 1999). LHb activation is associated with a wide range of negative affective processes (Ullsperger and von Cramon, 2003; Matsumoto and Hikosaka, 2007; Hikosaka et al., 2008; Jhou et al., 2009a; Shumake et al., 2010; Friedman et al., 2011; Li et al., 2011; Stamatakis and Stuber, 2012). These observations are consistent with the long-standing notion, as encapsulated in opponent process theory, that the dysphoria of acute drug abstinence is caused by compensatory adaptations acting in opposition to the drug's initial rewarding effects (Solomon and Corbit, 1974). In this theory, abused drugs produce rapid rewarding effects, while also activating slower aversive processes that outlast the initial reward, and that could involve either downregulation of reward mechanisms, or upregulation of "anti-reward" pathways (Koob and Le Moal, 2008a). The present findings suggest that the LHb and RMTg might contribute to the "anti-reward" processes postulated in this theory, particularly as LHb activation persists even after drug levels have declined in vivo or in vitro. However, the involvement of the LHb-RMTg circuit we propose in this regard does not preclude the participation of other mechanisms in opponency. Indeed, our finding that cocaine-induced RMTg c-Fos is still present (albeit reduced twofold) after FR lesions suggests that other nonhabenular RMTg afferents might also contribute to its responses to cocaine. For example, disruption of amygdala and extended amygdala function can also block cocaine-induced avoidance behavior in the runway task (Wenzel et al., 2011). Notably, these regions send direct and indirect projections to the RMTg (Jhou et al., 2009b; Kaufling et al., 2009), suggesting that multiple pathways may converge on the RMTg and contribute to cocaine's aversive conditioning (Fig. 8). Furthermore, longerterm drug intake can lead to alterations in stress and antistress systems, including dynorphin, nociceptin (also called orphanin FQ), CRF, and other signaling systems (Koob, 2008). Although interactions of habenulomesencephalic pathways with these particular stress-related systems are not well understood, it is notable that the RMTg expresses high levels of nociceptin/orphanin FQ (Jhou et al., 2012), suggesting another possible site of convergent interactions.

\section{Reciprocally inhibitory interactions between dopamine and anti-dopamine systems}

Although we focused most of our behavioral analysis on the implications of the LHb rebound excitations, the LHb's initial inhibitory responses to cocaine and DA are also striking, and may have implications for motivated behavior. The current findings, combined with previous reports of strong inhibitory effects of LHb and RMTg excitation on DA neurons (Christoph et al., 1986; Ji and Shepard, 2007; Hong et al., 2011), imply a mutually inhibitory relationship between DA systems and habenulomesencephalic systems (Fig. 8). Because DA and LHb neurons are activated by stimuli of opposite valence, this reciprocal inhibition suggests a possible substrate underlying prior findings that strong rewards initially inhibit processing of aversive stimuli, while conversely strong aversive stimuli can inhibit reward-seeking (Fields, 2007; Leknes and Tracey, 2008).

\section{Implications for tolerance and addiction}

Studies on addiction and tolerance often emphasize long-term adaptations occurring over weeks, months, and years. However, the shorter-term effects examined here could also influence addictive behavior, as it has been hypothesized that immediate aversive responses to acute drug withdrawal might confer a protective effect against addiction, helping to slow or prevent the transition from casual to compulsive drug use (Rezvani et al., 2010; Barrot et al., 2012). Prior studies have also noted that cocaine-induced RMTg activation continues to occur after prolonged drug administration (Perrotti et al., 2005; Jhou et al., 2009b), suggesting that the circuits examined here continue to influence long-term drug-seeking. Indeed, opponent process theories suggested that short-term activation of antireward systems may, with repeated exposure, develop into longer-term adaptations that contribute to tolerance, craving, and subsequent addiction (Koob and Le Moal, 2008a), and the current results suggest novel neural substrates to examine in relation to this hypothesis.

\section{References}

Balcita-Pedicino JJ, Omelchenko N, Bell R, Sesack SR (2011) The inhibitory influence of the lateral habenula on midbrain dopamine cells: ultrastructural evidence for indirect mediation via the rostromedial mesopontine tegmental nucleus. J Comp Neurol 519:1143-1164. CrossRef Medline

Barrot M, Sesack SR, Georges F, Pistis M, Hong S, Jhou TC (2012) Braking dopamine systems: a new GABA master structure for mesolimbic and nigrostriatal functions. J Neurosci 32:14094-14101. CrossRef Medline

Booze RM, Lehner AF, Wallace DR, Welch MA, Mactutus CF (1997) Dose- 
response cocaine pharmacokinetics and metabolite profile following intravenous administration and arterial sampling in unanesthetized, freely moving male rats. Neurotoxicol Teratol 19:7-15. CrossRef Medline

Burger C, Gorbatyuk OS, Velardo MJ, Peden CS, Williams P, Zolotukhin S, Reier PJ, Mandel RJ, Muzyczka N (2004) Recombinant AAV viral vectors pseudotyped with viral capsids from serotypes 1, 2, and 5 display differential efficiency and cell tropism after delivery to different regions of the central nervous system. Mol Ther 10:302-317. CrossRef Medline

Chang SY, Kim U (2004) Ionic mechanism of long-lasting discharges of action potentials triggered by membrane hyperpolarization in the medial lateral habenula. J Neurosci 24:2172-2181. CrossRef Medline

Chou TC, Bjorkum AA, Gaus SE, Lu J, Scammell TE, Saper CB (2002) Afferents to the ventrolateral preoptic nucleus. J Neurosci 22:977-990. Medline

Chow BY, Han X, Dobry AS, Qian X, Chuong AS, Li M, Henninger MA, Belfort GM, Lin Y, Monahan PE, Boyden ES (2010) High-performance genetically targetable optical neural silencing by light-driven proton pumps. Nature 463:98-102. CrossRef Medline

Christoph GR, Leonzio RJ, Wilcox KS (1986) Stimulation of the lateral habenula inhibits dopamine-containing neurons in the substantia nigra and ventral tegmental area of the rat. J Neurosci 6:613-619. Medline

Dougherty PM, Qiao JT, Wiggins RC, Dafny N (1990) Microiontophoresis of cocaine, desipramine, sulpiride, methysergide, and naloxone in habenula and parafasciculus. Exp Neurol 108:241-246. CrossRef Medline

Ettenberg A (2004) Opponent process properties of self-administered cocaine. Neurosci Biobehav Rev 27:721-728. CrossRef Medline

Ettenberg A, Bernardi RE (2007) Effects of buspirone on the immediate positive and delayed negative properties of intravenous cocaine as measured in the conditioned place preference test. Pharmacol Biochem Behav 87:171-178. CrossRef Medline

Ettenberg A, Geist TD (1993) Qualitative and quantitative differences in the operant runway behavior of rats working for cocaine and heroin reinforcement. Pharmacol Biochem Behav 44:191-198. CrossRef Medline

Ettenberg A, Raven MA, Danluck DA, Necessary BD (1999) Evidence for opponent-process actions of intravenous cocaine. Pharmacol Biochem Behav 64:507-512. CrossRef Medline

Fields HL (2007) Understanding how opioids contribute to reward and analgesia. Reg Anesth Pain Med 32:242-246. CrossRef Medline

Friedman A, Lax E, Dikshtein Y, Abraham L, Flaumenhaft Y, Sudai E, BenTzion M, Yadid G (2011) Electrical stimulation of the lateral habenula produces an inhibitory effect on sucrose self-administration. Neuropharmacology 60:381-387. CrossRef Medline

Geist TD, Ettenberg A (1997) Concurrent positive and negative goalbox events produce runway behaviors comparable to those of cocainereinforced rats. Pharmacol Biochem Behav 57:145-150. CrossRef Medline

Gruber C, Kahl A, Lebenheim L, Kowski A, Dittgen A, Veh RW (2007) Dopaminergic projections from the VTA substantially contribute to the mesohabenular pathway in the rat. Neurosci Lett 427:165-170. CrossRef Medline

Herkenham M, Nauta WJ (1979) Efferent connections of the habenular nuclei in the rat. J Comp Neurol 187:19-47. CrossRef Medline

Hikosaka O, Sesack SR, Lecourtier L, Shepard PD (2008) Habenula: crossroad between the basal ganglia and the limbic system. J Neurosci 28: 11825-11829. CrossRef Medline

Hong S, Jhou TC, Smith M, Saleem KS, Hikosaka O (2011) Negative reward signals from the lateral habenula to dopamine neurons are mediated by rostromedial tegmental nucleus in primates. J Neurosci 31:11457-11471. CrossRef Medline

Ikemoto S (2007) Dopamine reward circuitry: two projection systems from the ventral midbrain to the nucleus accumbens-olfactory tubercle complex. Brain Res Rev 56:27-78. CrossRef Medline

Jhou T (2005) Neural mechanisms of freezing and passive aversive behaviors. J Comp Neurol 493:111-114. CrossRef Medline

Jhou TC, Fields HL, Baxter MG, Saper CB, Holland PC (2009a) The rostromedial tegmental nucleus (RMTg), a GABAergic afferent to midbrain dopamine neurons, encodes aversive stimuli and inhibits motor responses. Neuron 61:786-800. CrossRef Medline

Jhou TC, Geisler S, Marinelli M, Degarmo BA, Zahm DS (2009b) The mesopontine rostromedial tegmental nucleus: a structure targeted by the lateral habenula that projects to the ventral tegmental area of Tsai and substantia nigra compacta. J Comp Neurol 513:566-596. CrossRef Medline

Jhou TC, Xu SP, Lee MR, Gallen CL, Ikemoto S (2012) Mapping of reinforcing and analgesic effects of the mu opioid agonist endomorphin-1 in the ventral midbrain of the rat. Psychopharmacology (Berl) 224:303-312. CrossRef Medline

Ji H, Shepard PD (2007) Lateral habenula stimulation inhibits rat midbrain dopamine neurons through a GABA(A) receptor-mediated mechanism. J Neurosci 27:6923-6930. CrossRef Medline

Kaufling J, Veinante P, Pawlowski SA, Freund-Mercier MJ, Barrot M (2009) Afferents to the GABAergic tail of the ventral tegmental area in the rat. J Comp Neurol 513:597-621. CrossRef Medline

Kenny PJ, Markou A (2001) Neurobiology of the nicotine withdrawal syndrome. Pharmacol Biochem Behav 70:531-549. CrossRef Medline

Kim U (2009) Topographic commissural and descending projections of the habenula in the rat. J Comp Neurol 513:173-187. CrossRef Medline

Knackstedt LA, Samimi MM, Ettenberg A (2002) Evidence for opponentprocess actions of intravenous cocaine and cocaethylene. Pharmacol Biochem Behav 72:931-936. CrossRef Medline

Koob GF (2008) A role for brain stress systems in addiction. Neuron 59:1134. CrossRef Medline

Koob GF, Le Moal M (2008a) Review: neurobiological mechanisms for opponent motivational processes in addiction. Philos Trans R Soc Lond B Biol Sci 363:3113-3123. CrossRef Medline

Koob GF, Le Moal M (2008b) Addiction and the brain antireward system. Annu Rev Psychol 59:29-53. CrossRef Medline

Koob GF, Stinus L, Le Moal M, Bloom FE (1989) Opponent process theory of motivation: neurobiological evidence from studies of opiate dependence. Neurosci Biobehav Rev 13:135-140. CrossRef Medline

Lammel S, Lim BK, Ran C, Huang KW, Betley MJ, Tye KM, Deisseroth K, Malenka RC (2012) Input-specific control of reward and aversion in the ventral tegmental area. Nature 491:212-217. CrossRef Medline

Lecca S, Melis M, Luchicchi A, Ennas MG, Castelli MP, Muntoni AL, Pistis M (2010) Effects of drugs of abuse on putative rostromedial tegmental neurons, inhibitory afferents to midbrain dopamine cells. Neuropsychopharmacology 36:589-602. CrossRef Medline

Leknes S, Tracey I (2008) A common neurobiology for pain and pleasure. Nat Rev Neurosci 9:314-320. CrossRef Medline

Li B, Piriz J, Mirrione M, Chung C, Proulx CD, Schulz D, Henn F, Malinow R (2011) Synaptic potentiation onto habenula neurons in the learned helplessness model of depression. Nature 470:535-539. CrossRef Medline

Liu ZH, Shin R, Ikemoto S (2008) Dual role of medial A10 dopamine neurons in affective encoding. Neuropsychopharmacology 33:30103020. CrossRef Medline

Ma F, Falk JL, Lau CE (1999) Within-subject variability in cocaine pharmacokinetics and pharmacodynamics after intraperitoneal compared with intravenous cocaine administration. Exp Clin Psychopharmacol 7:3-12. CrossRef Medline

Maroteaux M, Mameli M (2012) Cocaine evokes projection-specific synaptic plasticity of lateral habenula neurons. J Neurosci 32:1264112646. CrossRef Medline

Matsumoto M, Hikosaka O (2007) Lateral habenula as a source of negative reward signals in dopamine neurons. Nature 447:1111-1115. CrossRef Medline

Mutschler NH, Miczek KA (1998) Withdrawal from a self-administered or non-contingent cocaine binge: differences in ultrasonic distress vocalizations in rats. Psychopharmacology (Berl) 136:402-408. CrossRef Medline

Perrotti LI, Bolaños CA, Choi KH, Russo SJ, Edwards S, Ulery PG, Wallace DL, Self DW, Nestler EJ, Barrot M (2005) DeltaFosB accumulates in a GABAergic cell population in the posterior tail of the ventral tegmental area after psychostimulant treatment. Eur J Neurosci 21:2817-2824. CrossRef Medline

Rezvani AH, Sexton H, Levin ED (2010) Persistent high alcohol consumption in alcohol-preferring $(\mathrm{P})$ rats results from a lack of normal aversion to alcohol. Alcohol Alcohol 45:219-222. CrossRef Medline

Riley AL (2011) The paradox of drug taking: the role of the aversive effects of drugs. Physiol Behav 103:69-78. CrossRef Medline

Rothwell PE, Thomas MJ, Gewirtz JC (2009) Distinct profiles of anxiety and dysphoria during spontaneous withdrawal from acute morphine exposure. Neuropsychopharmacology 34:2285-2295. CrossRef Medline

Saper CB (1996) Any way you cut it: a new journal policy for the use of unbiased counting methods. J Comp Neurol 364:5. CrossRef Medline 
Shippenberg TS, Bals-Kubik R, Huber A, Herz A (1991) Neuroanatomical substrates mediating the aversive effects of $\mathrm{D}-1$ dopamine receptor antagonists. Psychopharmacology (Berl) 103:209-214. CrossRef Medline

Shumake J, Ilango A, Scheich H, Wetzel W, Ohl FW (2010) Differential neuromodulation of acquisition and retrieval of avoidance learning by the lateral habenula and ventral tegmental area. J Neurosci 30:58765883. CrossRef Medline

Solomon RL, Corbit JD (1973) An opponent-process theory of motivation: II. Cigarette addiction. J Abnorm Psychol 81:158-171. CrossRef Medline

Solomon RL, Corbit JD (1974) An opponent-process theory of motivation: I. Temporal dynamics of affect. Psychol Rev 81:119-145. CrossRef Medline

Stamatakis AM, Stuber GD (2012) Activation of lateral habenula inputs to the ventral midbrain promotes behavioral avoidance. Nat Neurosci 15: 1105-1107. CrossRef Medline

Ullsperger M, von Cramon DY (2003) Error monitoring using external feedback: specific roles of the habenular complex, the reward system, and the cingulate motor area revealed by functional magnetic resonance imaging. J Neurosci 23:4308-4314. Medline

Weiss F, Markou A, Lorang MT, Koob GF (1992) Basal extracellular dopamine levels in the nucleus accumbens are decreased during cocaine withdrawal after unlimited-access self-administration. Brain Res 593:314-318. CrossRef Medline

Weiss F, Parsons LH, Schulteis G, Hyytiä P, Lorang MT, Bloom FE, Koob GF (1996) Ethanol self-administration restores withdrawal-associated deficiencies in accumbal dopamine and 5-hydroxytryptamine release in dependent rats. J Neurosci 16:3474-3485. Medline

Wenzel JM, Waldroup SA, Haber ZM, Su ZI, Ben-Shahar O, Ettenberg A (2011) Effects of lidocaine-induced inactivation of the bed nucleus of the stria terminalis, the central or the basolateral nucleus of the amygdala on the opponent-process actions of self-administered cocaine in rats. Psychopharmacology (Berl) 217:221-230. CrossRef Medline

Wise RA, Bozarth MA (1987) A psychomotor stimulant theory of addiction. Psychol Rev 94:469-492. CrossRef Medline

Zahm DS, Becker ML, Freiman AJ, Strauch S, Degarmo B, Geisler S, Meredith GE, Marinelli M (2010) Fos after single and repeated selfadministration of cocaine and saline in the rat: emphasis on the basal forebrain and recalibration of expression. Neuropsychopharmacology 35 : 445-463. CrossRef Medline

Zimmer BA, Dobrin CV, Roberts DC (2011) Brain-cocaine concentrations determine the dose self-administered by rats on a novel behaviorally dependent dosing schedule. Neuropsychopharmacology 36 : 2741-2749. CrossRef Medline 